\title{
A SWIR based algorithm to retrieve total suspended matter in extremely turbid waters
}

\author{
E. Knaeps ${ }^{\text {a,* }}$, K.G. Ruddick ${ }^{\text {b }}$, D. Doxaran ${ }^{\text {c }}$, A.I. Dogliotti ${ }^{\text {d }}$, B. Nechad ${ }^{\text {b }}$, D. Raymaekers ${ }^{\text {a }}$, S. Sterckx ${ }^{\text {a }}$ \\ a Flemish Institute for Technological Research (VITO), Belgium \\ b Royal Belgian Institute for Natural Sciences (RBINS), Operational Directorate Natural Environments, Belgium \\ c Laboratoire d'Océanographie de Villefranche (LOV), UMR 7093, CNRS/UPMC, France \\ d Instituto de Astronomía y Física del Espacio (IAFE), CONICET/UBA, Argentina
}

\section{A R T I C L E I N F O}

\section{Article history:}

Received 27 November 2014

Received in revised form 5 June 2015

Accepted 26 June 2015

Available online 8 July 2015

\section{Keywords:}

Short Wave Infra Red

Water

Extremely turbid

Total Suspended Matter

\begin{abstract}
A B S T R A C T
In ocean colour remote sensing, the use of Near Infra Red (NIR) spectral bands for the retrieval of Total Suspended Matter (TSM) concentration in turbid and highly turbid waters has proven to be successful. In extremely turbid waters (TSM $>100 \mathrm{mg} \mathrm{L}^{-1}$ ) however, these bands are less sensitive to increases in TSM. Here it is proposed to use Short Wave Infra Red (SWIR) spectral bands between 1000 and $1300 \mathrm{~nm}$ for these extreme cases. This SWIR spectral region is subdivided into two regions, SWIR-I (1000 nm to $1200 \mathrm{~nm})$ and SWIR-II $(1200 \mathrm{~nm}$ to $1300 \mathrm{~nm}$ ) which correspond to local minima in the pure water absorption spectrum. For both spectral regions the water reflectance signal was measured in situ with an ASD spectrometer in three different extremely turbid estuarine sites: Scheldt (Belgium), Gironde (France), and Río de la Plata (Argentina), along with the TSM concentration. A measurable water reflectance was observed for all sites in SWIR-I, while in the SWIR-II region the signal was not significant compared to the Signal-to-Noise Ratio (SNR) of current Ocean Colour (OC) sensors. For the spectral band at $1020 \mathrm{~nm}$ (present in Ocean and Land Colour Instrument - OLCI, onboard Sentinel-3) and at $1071 \mathrm{~nm}$, an empirical single band TSM algorithm is defined which is valid for both the Gironde and Scheldt estuarine sites. This means that a single algorithm can be applied for both sites without expensive recalibration. The relationship between TSM and SWIR reflectance at 1020 and $1071 \mathrm{~nm}$ is linear and did not show any saturation for the concentrations measured here (up to $1400 \mathrm{mg} \mathrm{L}^{-1}$ ), while saturation was observed for the NIR wavelengths, as expected. Hence, for extremely turbid waters it is advised to switch from NIR to SWIR-I wavelengths to estimate TSM concentration. This was demonstrated for an airborne hyperspectral dataset (Airborne Prism Experiment, APEX) from the Gironde estuary having several spectral bands in the SWIR-I. The empirical single band SWIR TSM algorithm was applied to the atmospherically corrected scene providing a TSM concentration map of the Gironde from mouth to more upstream with concentrations expected in this region ranging from a few to several hundreds $\mathrm{mg} \mathrm{L}^{-1}$. These results, i.e. the existence of a single relationship for the Scheldt and Gironde, not showing any decrease of sensitivity, highlights the importance of having SWIR bands in future ocean colour sensors for studying extremely turbid rivers, coastal areas and estuaries in the world. A further implication of these results is that there is a TSM limit for application of atmospheric correction algorithms which assume zero SWIR marine reflectance. That limit is defined here as function of wavelength and sensor noise level.
\end{abstract}

(C) 2015 Elsevier Inc. All rights reserved.

\section{Introduction}

\subsection{Background}

In recent years the use of Short Wave Infra Red (SWIR) bands for processing remotely sensed imagery in extremely turbid waters (i.e. waters with Total Suspended Matter - TSM concentration $>100 \mathrm{mg} \mathrm{L}^{-1}$ ) has gained increasing attention. In particular, its use in

\footnotetext{
* Corresponding author at: Flemish Institute for Technological Research (VITO), Belgium.

E-mail address: els.knaeps@vito.be (E. Knaeps).
}

atmospheric correction assuming a black pixel in several SWIR bands (e.g. the SWIR based algorithm by Wang \& Shi, 2007) has been of great importance. By assuming that the water reflectance is negligible in these SWIR bands, they can be used to estimate the aerosol contribution to the Top Of Atmosphere (TOA) signal. This has shown to be a good alternative to existing Near Infra Red (NIR) based approaches (Chen, Yin, Xiao, Xu, \& Lin, 2014; Dogliotti, Ruddick, Nechad, \& Lasta, 2011).

Further research has shown that, in extremely turbid waters and in spectral regions with lower pure water absorption (e.g. around $1070 \mathrm{~nm}$ ), this black pixel assumption is not always valid and a radiance contribution from the water can be expected. In this case, the particulate light backscattering compensates the light absorption by pure water. 
Evidence of non-zero reflectance in the SWIR was presented for the $1240 \mathrm{~nm}$ band by the analysis of MODIS imagery (e.g. Shi \& Wang, 2009,2014 ), but this has not been further verified with in situ measurements. For shorter SWIR wavelengths (950-1150 nm), in situ measurements have been presented and revealed a significant water reflectance signal (Knaeps, Raymaekers, Sterckx, Ruddick, \& Dogliotti, 2012). In addition, it was suggested that these spectral bands could be used for deriving TSM concentration in extremely turbid waters. This is of great interest since it is known that bands at shorter wavelengths saturate in these waters (e.g. Nechad, Ruddick, \& Park, 2010; Shen et al., 2010) resulting in much less or no sensitivity of the water reflectance $\left(\mathrm{R}_{\mathrm{w}}\right)$ to an increase in TSM leading to less accurate estimates of the TSM concentration from remotely sensed imagery.

This paper aims to develop a SWIR based TSM algorithm for extremely turbid waters. It is based on an extensive in situ dataset, including TSM concentration measurements and water reflectance spectra in the range $350-2500 \mathrm{~nm}$, in three extremely turbid estuarine waters: Scheldt (Belgium), Gironde (France) and Río de la Plata (Argentine). First, the SWIR water reflectance in these three areas is characterized and particular bands of interest are defined. Then, an empirical algorithm is developed based on the in situ measurements of the water reflectance and corresponding TSM concentrations. Further we investigate whether the established relationship (further referred to as the empirical SWIR TSM algorithm) holds in different regions and seasons. The performance of the empirical SWIR-based TSM algorithm is compared with an existing semi-analytical TSM algorithm with parameters extrapolated for the SWIR. As a side product, the TSM ranges where the black pixel assumption can be applied, are derived from the established SWIR TSM algorithm. Finally, the SWIR-based algorithm is applied to an airborne dataset of the Gironde river.

\subsection{The SWIR TSM algorithm: expected relationship and parameterization}

Based on existing theoretical studies for the NIR (e.g. Ruddick, Cauwer, Park, \& Moore, 2006) and empirically derived relationships between TSM and reflectance in the NIR, the SWIR marine reflectance is expected to be very simply characterized, i.e. the magnitude of reflectance at any given wavelength will be a function of particulate backscatter and hence TSM and the spectral shape of reflectance will be determined by the inverse of the pure water absorption coefficient. In general, an increase in TSM leads to an increase in the particulate backscattering and absorption coefficients. In the SWIR, this will result in an increase in water reflectance because absorption is almost independent of dissolved and particulate matter in the SWIR. Knaeps et al. (2012) found a linear relationship between reflectance at 1071 and $1020 \mathrm{~nm}$ and TSM concentration for a TSM range between 15 and $402 \mathrm{mg} \mathrm{L}^{-1}$. It is expected that, when moving to more turbid waters, the relationship between reflectance and TSM will become non-linear, but this will occur at much higher TSM concentrations than for the NIR because of the higher pure water absorption. This saturation effect has been observed for red (Bowers, Boudjelas, \& Harker, 1998) and NIR wavelengths (e.g. Doxaran, Froidefond, Lavender, \& Castaing, 2002; Nechad et al., 2010). For instance, Nechad et al. (2010) derived a model between reflectance and TSM with a linear relationship for low concentrations of TSM and asymptotic limit at higher TSM based on a spectral reflectance model. They found that this asymptotic limit will be attained at higher concentrations when going to longer wavelengths. This was also shown in a tank experiment by Shen et al. (2010). This experiment showed first a rapid increase of the reflectance with increasing TSM (up to $150 \mathrm{mg} \mathrm{L}^{-1}$ ) and then a logarithmic increase (TSM from $150 \mathrm{mg} \mathrm{L}^{-1}$ up to $2500 \mathrm{mg} \mathrm{L}^{-1}$ ).

Although it is expected that the SWIR could be very useful for very high concentrations of TSM due to the higher sensitivity of the water reflectance $\left(R_{W}\right)$ compared to shorter wavelengths, the SWIR might not be suited for low concentrations because of the low signal. The increase in the pure water absorption will require increasing TSM to ensure a sufficient reflectance signal (Ruddick et al., 2006) while less absorbing portions of the spectrum are more suitable for low TSM concentrations. This has led to the development of multi wavelength switching algorithms adapted to the magnitude of the TSM concentration. Shen et al. (2010) proposed switching between 560, 650, 709 and 779 nm MERIS bands for TSM thresholds of 20,80 and $250 \mathrm{mg} \mathrm{L}^{-1}$ (or remote sensing reflectance $-\mathrm{R}_{\mathrm{rs}}$-thresholds of $0.01,0.023$ and $0.033 \mathrm{sr}^{-1}$ for the corresponding wavelengths).

The validity of these single band semi-analytical TSM algorithms may be restricted to a specific region. New parameterization of the algorithm might be needed for other sites due to changes in particle type and composition. There are examples of publications which found robust algorithms and little variability in the Inherent Optical Properties (IOPs) spectral shape for different regions and seasons (e.g. Aurin, Dierssen, Twardowski, \& Roesler, 2010), but many highlight the need for new parameterization (Doxaran et al., 2002; Islam, Begun, Yamaguchi, \& Ogawa, 2001). Furthermore, when the sites are highly dynamic, a single parameterization of the relationship might even not be possible within one region. Aurin and Dierssen (2012) and Blondeau-Patissier, Brando, Oubelkheir, Dekker, Clementson and Daniel (2009), for example, showed the existence of multiple optical domains within one region.

Very recently, an alternative to these regional TSM algorithms was presented by Dogliotti, Ruddick, Nechad, Doxaran, and Knaeps (2015). They developed a global Turbidity ( $\mathrm{T}$ ) algorithm using an NIR band at $859 \mathrm{~nm}$ and suggest deriving a regional TSM algorithm by using the global T algorithm with a regional relationship to convert T to TSM. The existence of such a global T algorithm is supported by the fact that $\mathrm{T}$, in contrast to TSM, is an optical property and is, hence, less sensitive to the particle composition.

\section{Methodology}

\subsection{Naming conventions}

In this paper, a small part of the SWIR region, between $1000 \mathrm{~nm}$ and $1300 \mathrm{~nm}$, is evaluated. Beyond $1300 \mathrm{~nm}$ the pure water absorption is so high that no signal is expected for optically deep waters even for the most turbid waters in the world. The pure water absorption (Kou, Labrie, \& Chylek, 1993; Pope \& Fry, 1997) and atmospheric transmittance for this spectral region are shown in Fig. 1. The grey dots represent wavelengths of interest which are discussed further in the manuscript. Based on the shape and magnitude of the pure water absorption within the 1000-1300 nm region two specific areas of interest, further denoted

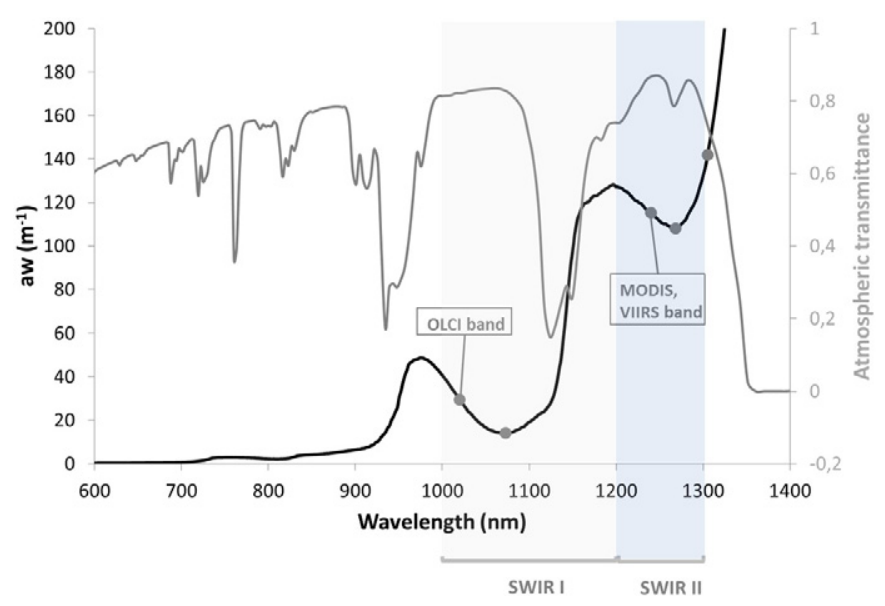

Fig. 1. Pure water absorption coefficient (Kou et al., 1993; Pope \& Fry, 1997) and total oneway atmospheric transmittance simulated using the Modtran radiative transfer code for a platform height of $800 \mathrm{~km}$, a nadir view, a visibility of $17 \mathrm{~km}$, a water vapour content of $2.5 \mathrm{~m}^{-1}$ and a rural aerosol. Spectral band of interest are also shown as grey round symbols (1020 nm OLCI band, $1071 \mathrm{~nm}, 1240 \mathrm{~nm}$ MODIS band, $1270 \mathrm{~nm}$, and $1300 \mathrm{~nm}$ ). 
Table 1

Sensors with wavelengths in SWIR-I and/or SWIR-II.

\begin{tabular}{|c|c|c|c|c|c|}
\hline Sensor & SWIR-I bands (nm) & SWIR-II bands (nm) & Bandwidth (nm) & $\mathrm{L}_{\mathrm{ref}}(\mathrm{W} /(\mathrm{m} 2 \mathrm{sr} \mu \mathrm{m}))$ & $\mathrm{SNR@L} \mathrm{L}_{\mathrm{ref}}$ \\
\hline Sentinel-3 OLCI & 1020 & / & 40 & 3.86 & 152 \\
\hline MODIS & / & 1240 & 20 & 5.4 & 74 \\
\hline VIIRS & / & 1240 & 20 & 5.4 & 74 \\
\hline WorldView-3 & / & 1210 & 30 & Not specified & Not specified \\
\hline Enmap HSI & Hyperspectral & Hyperspectral & & & \\
\hline Hyspiri & Hyperspectral & Hyperspectral & & & \\
\hline CIMEL CE-318 & 1020 & / & 10 & Variable & Variable gain \\
\hline
\end{tabular}

Source: https://earth.esa.int/, http://modis.gsfc.nasa.gov/about/specifications.php.

as SWIR-I and SWIR-II are identified. The SWIR-I region ranges from $1000 \mathrm{~nm}$ (pure water absorption $a_{w}$ at $1000 \mathrm{~nm}=40.7 \mathrm{~m}^{-1}$ ) to $1200 \mathrm{~nm}$, close to the local maximum in the pure water absorption $\left(a_{w}\right.$ at $\left.1200 \mathrm{~nm}=127.2 \mathrm{~m}^{-1}\right)$. The SWIR-II region ranges from $1200 \mathrm{~nm}$ to $1300 \mathrm{~nm}$ where the pure water absorption reaches a value of $132.2 \mathrm{~m}^{-1}$. The minimum water absorption in these two regions is observed at $1073 \mathrm{~nm}\left(a_{w}=14,05 \mathrm{~m}^{-1}\right)$ and $1270 \mathrm{~nm}\left(a_{w}=\right.$ $108 \mathrm{~m}^{-1}$ ). Water absorption at $1020 \mathrm{~nm}$, a wavelength typical of the limits of silicon based detectors, has been measured by Kou et al. (1993) as $a_{w}=29.57 \mathrm{~m}^{-1}$, slightly higher than at $1073 \mathrm{~nm}$. As shown by Röttgers et al. (2012), the sensitivity of these values in the SWIR-I and SWIR-II to temperature and salinity is higher than in the Visible and NIR wavelengths.

Table 1 provides an overview of current and future satellite sensors with spectral bands in these two SWIR regions and their corresponding Signal-to-Noise Ratio (SNR) at a reference radiance $\left(\mathrm{L}_{\mathrm{ref}}\right)$. This overview is limited to sensors with appropriate characteristics for water quality monitoring. The CIMEL CE-318 ground-based radiometer is added because, as part of the ocean colour component of the Aerosol Robotic Network (AERONET-OC; Zibordi et al., 2009), it provides in situ standardized measurements of water leaving radiance important for satellite ocean colour validation activities.
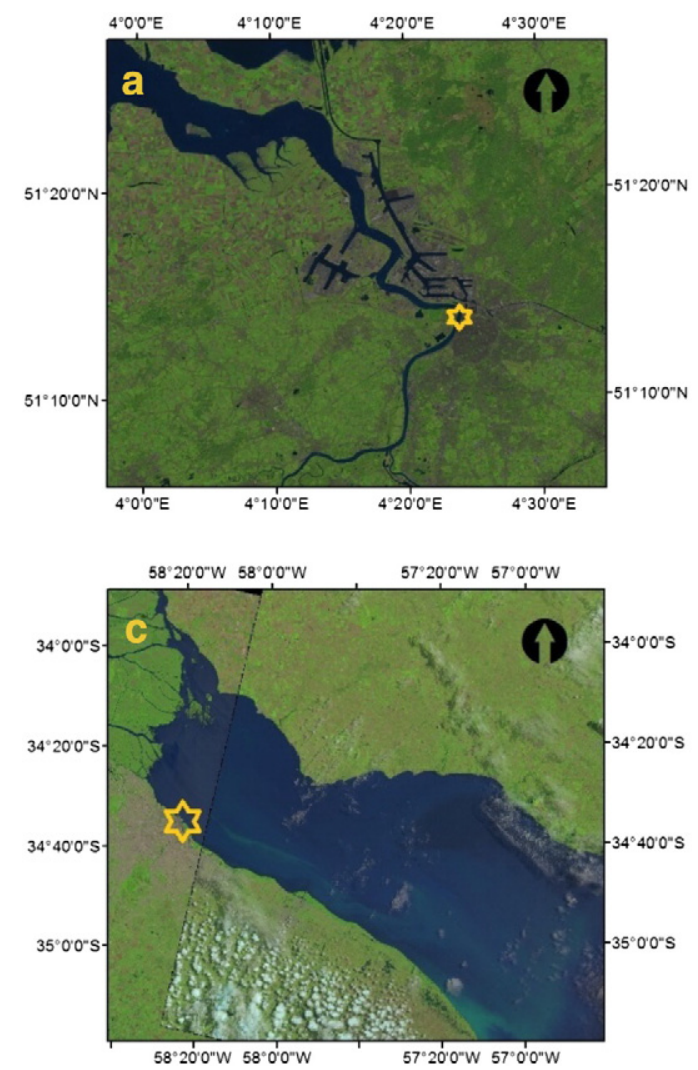

\subsection{The study areas: the Scheldt, Gironde and Río de la Plata estuaries}

Field data collection has been performed in three different estuaries associated with high to extremely high TSM concentrations where particulate light backscattering is expected to be high enough to result in a significant water reflectance signal in the SWIR. The three estuarine sites are: the Scheldt in Belgium, the Gironde in France and the Río de la Plata in Argentina (Fig. 2). These three estuaries were chosen because of their high concentration range of suspended particles and diversity of particle composition/type.

The Scheldt River originates in France, flows through Belgium and reaches the North Sea in the Netherlands. It is a highly dynamic river leading to TSM concentrations varying from a few to several hundreds $\mathrm{mg} \mathrm{L}^{-1}$ during one tidal cycle. In the middle estuary, where the study area is located, there is a tide-dominated Maximum Turbidity Zone (MTZ). Here, high suspended matter concentration is mainly attributed to the re-suspension of local bottom sediments induced by the tidal current (Chen, Wartel, Van Eck, \& Van Maldegem, 2005).

The Gironde is a macrotidal estuary where the water optical properties are dominated by non-algal particles, i.e. by suspended sediments (silts and clays) delivered by the Garonne and Dordogne Rivers and trapped within the maximum turbidity zone of the estuary. TSM

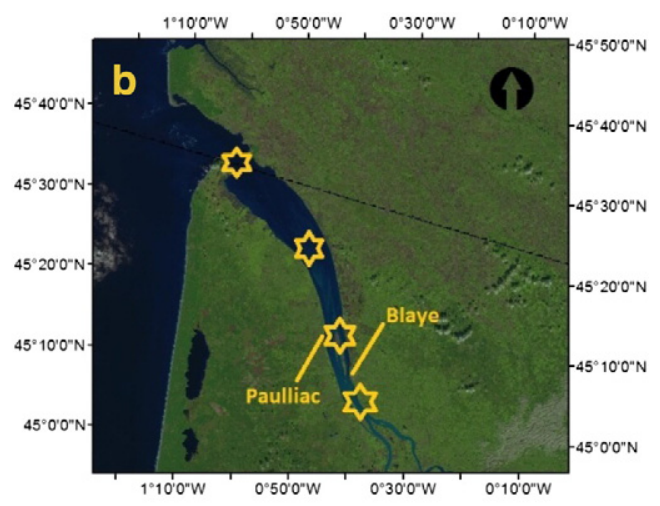

Fig. 2. Landsat8-OLI images composites for a) Scheldt, Belgium b) Gironde, France c) Río de La Plata, Argentina. 
Table 2

Characterization of test sites.

\begin{tabular}{|c|c|c|c|c|c|}
\hline & \multirow{2}{*}{$\begin{array}{l}\text { TSM organic } \\
\text { fraction }\end{array}$} & \multicolumn{2}{|l|}{ TSM inorganic fraction } & \multirow[t]{2}{*}{ Tidal regime } & \multirow[t]{2}{*}{ Estuary cross section width } \\
\hline & & Mineralogy classification & Textural & & \\
\hline Scheldt & $8.5-25 \%$ & $\begin{array}{l}\text { Quartz, calcite, clay minerals } \\
\text { (illite, montmorillonite, kaolinite and chlorite) }\end{array}$ & $\begin{array}{l}\text { Silty clays with low amount of } \\
\text { sand but high amount of clay }\end{array}$ & Macrotidal (tidal range $\mathrm{H}>4 \mathrm{~m}$ ) & $\begin{array}{l}\text { Vlissingen } 4,5 \mathrm{~km} \text {, } \\
\text { Antwerp 0,38 km }\end{array}$ \\
\hline Gironde & $1,8 \%$ & $\begin{array}{l}98 \% \text { : } 63 \% \text { micas, } 25 \% \text { quartz and } 12 \% \text { clays: } \\
\text { montmorillonite ( } 30 \%) \text {, illite ( } 40 \%) \text {, } \\
\text { kaolinite (15\%) and chlorite ( } 15 \%)\end{array}$ & $75 \%$ silt and clay, $25 \%$ sand & Macrotidal (tidal range $\mathrm{H}>4 \mathrm{~m}$ ) & Royan 5,3 km, Blaye 3,1 km \\
\hline La Plata & $10-25 \%$ & $\begin{array}{l}\text { Quartz, mica, plagioclase and K-feldspar. The } \\
\text { clay-size mineralogy show abundant illite } \\
\text { (40\%) and montmorillonite (30\%), } \\
\text { and lesser amount of kaolinite and chlorite }\end{array}$ & $90 \%$ silt and $10 \%$ clay & Microtidal (tidal range $\mathrm{H}<2 \mathrm{~m}$ ) & Buenos Aires 48,5 km \\
\hline
\end{tabular}

Source: Chen et al. (2005); Latouche (1971); Etcheber (1978); Castaing (1981); López Laborde \& Nagy (1999); Depetris \& Griffin (1968).

concentrations typically vary from ten to four thousands $\mathrm{mg} \mathrm{L}^{-1}$ within surface waters, mainly depending on fortnightly tidal cycles (Doxaran, Froidefond, Castaing, \& Babin, 2009).

The Río de la Plata is a shallow $(<20 \mathrm{~m})$ and large-scale estuary which drains the second largest basin in South America. High values of Total Suspended Matter have been reported in this region, with mean values ranging from 100 to $300 \mathrm{mg} \mathrm{L}^{-1}$ and extreme concentrations up to $400 \mathrm{mg} \mathrm{l}^{-1}$ (C.A.R.P., 1989). This area has been identified by a number of investigators (Doerffer, 2006; Doron, Bélanger, Doxaran, \& Babin, 2011; Moore, Lavender, Kratzer, Icely, \& Huot, 2010; Shi \& Wang, 2009) as a useful very bright target for assessment of atmospheric correction algorithms, so far tested without any in situ data (Dogliotti et al., 2011).

Table 2 highlights the differences in the estuary cross section, suspended sediment composition and tidal regime for the three study sites.

\subsection{Data collection}

In situ data were collected during 5 different campaigns in the period 2010-2013 (Table 3). Most of the data were collected from fixed pontoons along the side of the estuaries with large variation in coloured water constituent concentrations during the tidal cycle. When compared to ship-based data such fixed platforms can give better data quality as regards viewing geometry (particularly verticality of irradiance sensors or horizontality of reflectance plaques used to estimate the downwelling irradiance signal), although the range of acceptable azimuth viewing angles can be more limited because of greater risks of optical contamination (shadow/reflection) of the target water by the platform itself. During the Gironde 2012 campaign additional measurements were made from a vessel to sample further downstream up to the mouth of the estuary.

The total number of samples for each campaign is shown in Table 3. This number refers to the number of water reflectance $\left(R_{w}\right)$ samples retained after quality control. In total 137 samples were made, 32 in the Scheldt, 72 in the Gironde, and 33 in Río de la Plata.

\subsubsection{In situ measurements}

Table 4 lists the in situ measurements made at each sampling campaign. For all campaigns comprising 137 samples, water reflectance $\left(\mathrm{R}_{\mathrm{w}}\right)$, TSM concentration (TSM), salinity (Sal) and temperature (Temp) were measured. Turbidity ( $\mathrm{T}$ ) was measured in all campaigns, but for a lower number of samples. Chlorophyll-a (Chla) concentration and IOPs (absorption of particles, $a_{p}$; absorption of non-algae particles, $a_{\text {nap }}$; absorption of phytoplankton, $a_{\text {phyt }}$; backscattering of particles, $b_{b p}$ ) are available for each site, but for a reduced number of samples.

The measurement methodology for the main in situ measurements is described below.

2.3.1.1. Water reflectance. Water reflectance $\left(R_{\mathrm{w}}\right)$ between 350 and $2500 \mathrm{~nm}$ was measured with an ASD Fieldspec FR spectrometer. The detailed measurement methodology is described in Knaeps et al. (2012).

Table 3

Time and location of in situ campaigns.

\begin{tabular}{|c|c|c|c|}
\hline Date & Station & Number of $\mathrm{R}_{\mathrm{w}}$ samples $(\mathrm{N})$ & Information \\
\hline \multicolumn{4}{|c|}{ Campaign: Scheldt 2010} \\
\hline $15 / 07 / 2010$ & Sint Anna & 7 & Pontoon $\left(51^{\circ} 14^{\prime} 01^{\prime \prime} \mathrm{N}\right.$ and $\left.4^{\circ} 23^{\prime} 50^{\prime \prime} \mathrm{E}\right)$ \\
\hline $26 / 10 / 2010$ & Sint Anna & 8 & \\
\hline \multicolumn{4}{|c|}{ Campaign: Scheldt 2012} \\
\hline $02 / 06 / 2012$ & Sint Anna & 6 & Pontoon $\left(51^{\circ} 14^{\prime} 01^{\prime \prime} \mathrm{N}\right.$ and $\left.4^{\circ} 23^{\prime} 50^{\prime \prime} \mathrm{E}\right)$ \\
\hline 05/06/2012 & Sint Anna & 11 & \\
\hline \multicolumn{4}{|c|}{ Campaign: Gironde 2012} \\
\hline $11-13 / 06 / 2012$ & Onboard the research vessel & 15 & $\begin{array}{l}3 \text { locations: } 85 \mathrm{~km}, 67 \mathrm{~km} \text { and } 30 \mathrm{~km} \text { downstream Bordeaux } \\
\left(45^{\circ} 31^{\prime} 000^{\prime \prime} \mathrm{N} \text { and } 01^{\circ} 57^{\prime} 000^{\prime \prime} \mathrm{W} \text {, }\right. \\
45^{\circ} 22^{\prime} 300^{\prime \prime} \mathrm{N} \text { and } 00^{\circ} 48^{\prime} 100^{\prime \prime} \mathrm{W} \\
\left.45^{\circ} 04^{\prime} 100^{\prime \prime} \mathrm{N} \text { and } 00^{\circ} 38^{\prime} 300^{\prime \prime} \mathrm{W}\right)\end{array}$ \\
\hline $14 / 06 / 2012$ & Blaye & 15 & Pontoon, East shore of the estuary $\left(45^{\circ} 07^{\prime} 37^{\prime \prime} \mathrm{N}\right.$ and $\left.0^{\circ} 39^{\prime} 47^{\prime \prime} \mathrm{W}\right)$ \\
\hline $15-16 / 06 / 2012$ & Paulliac & 15 & Pier, West shore of the estuary $\left(45^{\circ} 12^{\prime} 00^{\prime \prime} \mathrm{N}\right.$ and $\left.0^{\circ} 44^{\prime} 33^{\prime \prime} \mathrm{W}\right)$ \\
\hline \multicolumn{4}{|c|}{ Campaign: Gironde 2013} \\
\hline $16 / 08 / 2013$ & Blaye & 4 & Pontoon, right shore of the estuary $\left(45^{\circ} 07^{\prime} 37^{\prime \prime} \mathrm{N}\right.$ and $\left.0^{\circ} 39^{\prime} 47^{\prime \prime} \mathrm{W}\right)$ \\
\hline $12-15 / 08 / 2013$ & Paulliac & 23 & Pier, left shore of the estuary $\left(45^{\circ} 12^{\prime} 00^{\prime \prime} \mathrm{N}\right.$ and $\left.0^{\circ} 44^{\prime} 33^{\prime \prime} \mathrm{W}\right)$ \\
\hline \multicolumn{4}{|c|}{ Campaign: La Plata 2012} \\
\hline $15-23 / 11 / 2012$ & Club de Pescadores Pier & 33 & Pier $\left(34^{\circ} 33^{\prime} 39 \mathrm{~S}\right.$ and $\left.58^{\circ} 23^{\prime} 56^{\prime \prime} \mathrm{W}\right)$ \\
\hline
\end{tabular}


Table 4

Time and location of in situ campaigns.

\begin{tabular}{lllllllllll}
\hline Campaign & $\mathrm{R}_{\mathrm{w}}$ & TSM & $\mathrm{T}$ & Chla & Sal & Temp & $\mathrm{a}_{\text {nap }}$ & $\mathrm{a}_{\mathrm{p}}$ & $\mathrm{a}_{\text {phyt }}$ & $\mathrm{b}_{\mathrm{bp}}$ \\
\hline Scheldt 2010 & X & X & X & & X & X & & & & \\
Scheldt 2012 & X & X & X & X & X & X & X & X & X & X \\
Gironde 2012 & X & X & X & X & X & X & & X & & X \\
Gironde 2013 & X & X & X & & X & X & & X & & X \\
La Plata 2012 & X & X & X & & X & X & & X & & X \\
\hline
\end{tabular}

The reflectance $\left(\mathrm{R}_{\mathrm{w}}\right)$ was calculated using the following equation (Mobley, 1999):

$\mathrm{R}_{\mathrm{w}}(\lambda)=\pi\left(\mathrm{L}_{\mathrm{u}}(\mathrm{a}, \lambda)-\rho_{\mathrm{as}} \mathrm{L}_{\mathrm{sky}}(\mathrm{a}, \lambda)\right) / \mathrm{E}_{\mathrm{d}}(0+, \lambda)$.

Where $L_{u}(a, \lambda)$ is the total upwelling radiance from the water, $\mathrm{E}_{\mathrm{d}}(0+, \lambda)$ is the downwelling irradiance above the surface, $\mathrm{L}_{\text {sky }}(\mathrm{a}, \lambda)$ is the downwelling sky radiance, and $\rho_{\mathrm{as}}$ is the air-sea interface reflection coefficient which is set to a fixed value of 0.0256. $\rho_{\text {as }}$ is not calculated based on the wind speed as in Ruddick et al. (2006) because surface gravity waves are not expected to be as strongly wind speed dependent in a narrow estuary. An extra white reflectance correction was performed for residual sky glint by subtracting the water reflectance at $1305 \mathrm{~nm}$. It was chosen here to use a wavelength further in the SWIR compared to the one used in Knaeps et al. (2012) (i.e. $1200 \mathrm{~nm}$ ), because there may be non-zero reflectance at shorter wavelengths in the highly turbid waters found in the study sites. At $1305 \mathrm{~nm}$ the absorption of pure water $\left(a_{w}\right)$ is $141.8 \mathrm{~m}^{-1}$ (Fig. 1, wavelength indicated with grey dot) which is higher than the absorption of pure water at $1240 \mathrm{~nm}$ $\left(a_{w}=115.4 \mathrm{~m}^{-1}\right)$ where a small radiance contribution was observed for the Yangtze (Shi \& Wang, 2009). Therefore, it is reasonable to expect non zero water reflectance at $1305 \mathrm{~nm}$. Beyond $1305 \mathrm{~nm}$ spectra are too noisy because of atmospheric absorption.

Although the ASD, having only one radiometer, is not designed for measuring water reflectance, inter comparisons with a 3-sensor Trios system (400-900 nm) in the Visible/NIR (Ruddick et al., 2006) gave satisfactory results $(R=0.99$, Root-Mean-Square error, $\mathrm{RMSE}=0.006$ )
(Knaeps et al., 2012). Here, the Trios system was also deployed for additional quality control of the ASD water reflectance spectra.

2.3.1.2. TSM concentration and turbidity. Coincident with the water reflectance measurements, water samples were collected just beneath the water surface in dark brown bottles. Turbidity was directly measured on the water samples, which were then filtered on site and stored for TSM analysis.

The turbidity was measured with a portable HACH 2100P ISO turbidimeter using the same protocol as in Dogliotti et al. (2015). Three replicate measurements were recorded for each sample. The turbidity data was used here for quality control of the TSM data.

The filters for the TSM analysis (Whatman GF/F filters with a nominal pore size of $0.7 \mu \mathrm{m}$ ) were first prepared in the laboratory. They were left for $1 \mathrm{~h}$ in Milli-Q water and then gently shaken with cleaned Millipore forceps to remove residual fibres. They were placed in an aluminium plate and ashed for $1 \mathrm{~h}$ at $450{ }^{\circ} \mathrm{C}$, then dried for $12 \mathrm{~h}$ at $60{ }^{\circ} \mathrm{C}$ in an oven prior to weighing in a dry atmosphere. The filters were stored in clean Petri dishes. Known volumes of water ( 3 to $100 \mathrm{ml}$ ) were filtered in triplicate through the pre-ashed and preweighed glass-fibre filters at low vacuum. Each filter was then rinsed with Milli-Q water $(250 \mathrm{ml})$. The filters were stored in a freezer and then transported in dry ice to the laboratories (LOV and/or VITO). Here they were temporarily stored at $-80^{\circ} \mathrm{C}$. Finally they were dried for $24 \mathrm{~h}$ at $60^{\circ} \mathrm{C}$ and weighed again in a dry atmosphere.

Systematically the water samples were filtered in triplicates in order to determine the precision of the TSM concentration measurements. After removal of outliers the mean value of the triplicates was used for further analysis.

\subsubsection{Hyperspectral airborne image acquisitions}

Several Airborne Prism EXperiment (APEX) flight lines were acquired along the Gironde estuary on 14 June 2012 under sunny conditions. That day, in situ sampling was performed at the pontoon of Blaye.

APEX records hyperspectral data between 350 and $2500 \mathrm{~nm}$. In the SWIR-I and SWIR-II spectral regions (975-1300 nm) APEX has $31 \mathrm{spec}-$ tral bands with a Full Width at Half Maximum (FWHM) between 11 and

Table 5

Constituent concentration ranges for all three study sites.

\begin{tabular}{|c|c|c|c|c|c|}
\hline Study area & $\mathrm{TSM}\left(\mathrm{mg} \mathrm{L}^{-1}\right)$ & Turbidity (FNU) & Chla $\left(\mu \mathrm{g} \mathrm{L}^{-1}\right)$ & Salinity (psu) & Temperature $\left({ }^{\circ} \mathrm{C}\right)$ \\
\hline Scheldt 2010 & $15-402$ & $54-283$ & / & $2.7-10.4$ & $23.5-23.8$ \\
\hline Scheldt 2012 & $49-365$ & $48-371$ & $16-71$ & $1.1-6.4$ & $18.5-19.7$ \\
\hline Gironde 2012 & $56-1400$ & 256-1919 & $0.9-4.2$ & $0.1-20.8$ & $18.4-21$ \\
\hline La Plata & $30-160$ & $60-186$ & / & $0.15-0.19$ & $23-26.9$ \\
\hline Gironde 2013 & $68-1190$ & $41-1422$ & / & $1.7-7.5$ & $21.3-26$ \\
\hline
\end{tabular}
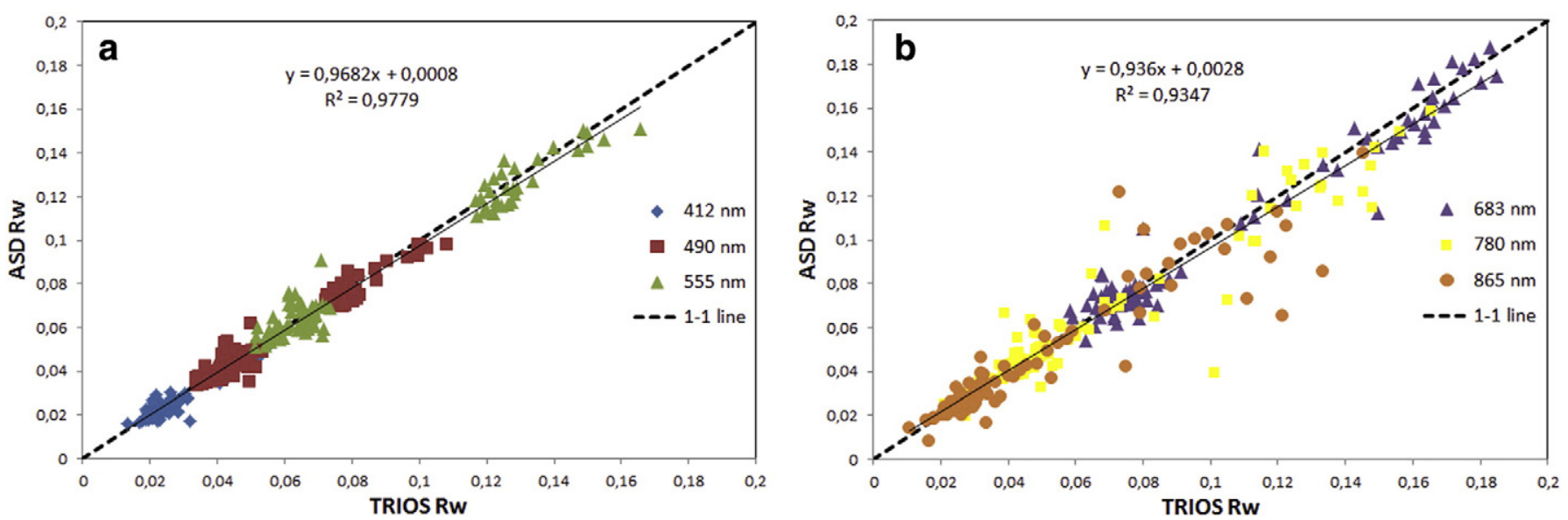

Fig. 3. Intercomparison between $A S D R_{w}$ and Trios $R_{w}$ for a) wavelengths at 412,490 and $555 \mathrm{~nm}$ and b) wavelengths at 683,780 and $865 \mathrm{~nm}$. 

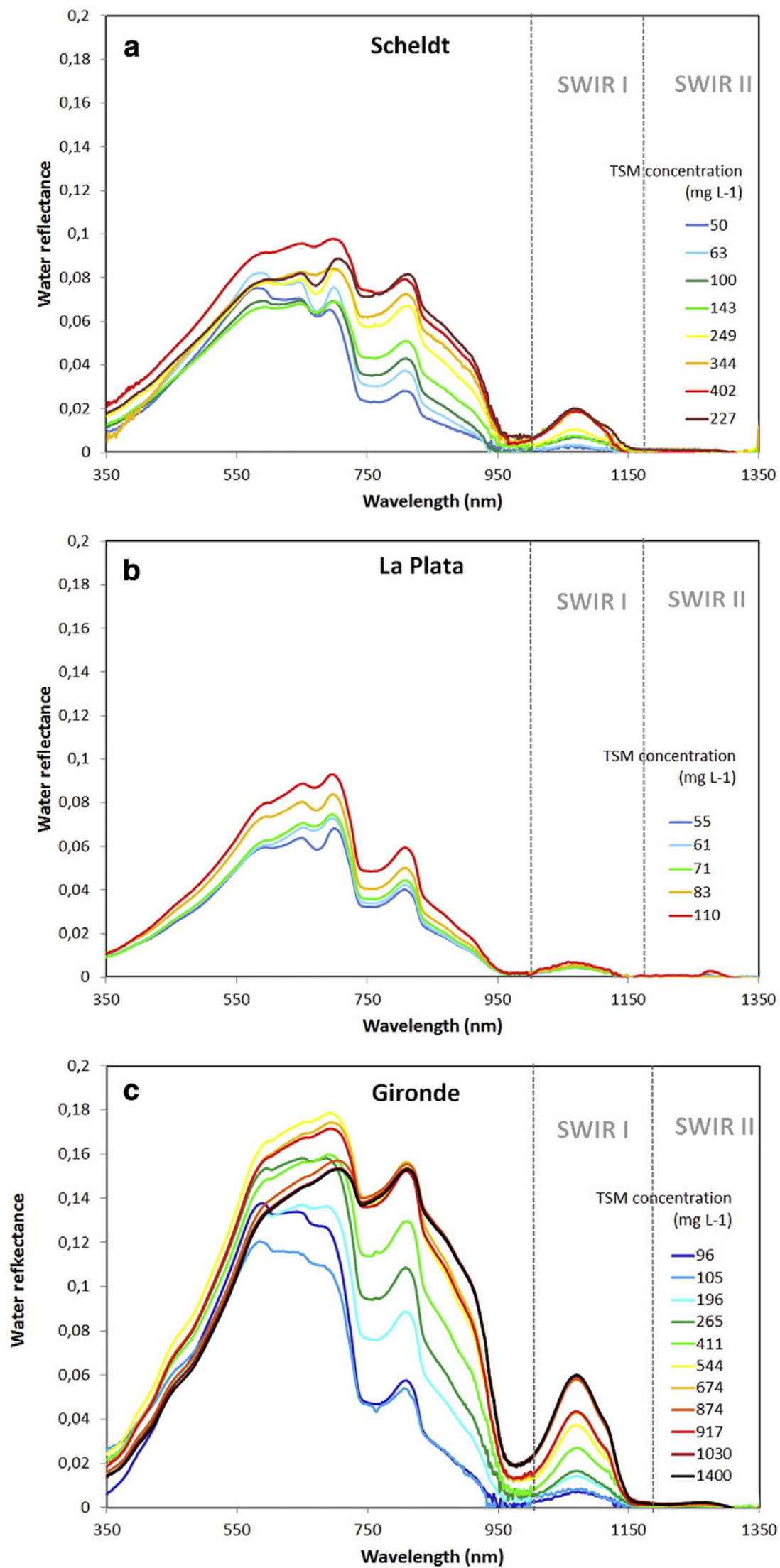

Fig. 4. Typical water reflectance spectra for a) Scheldt, b) Río de la Plata, and c) Gironde estuaries. 

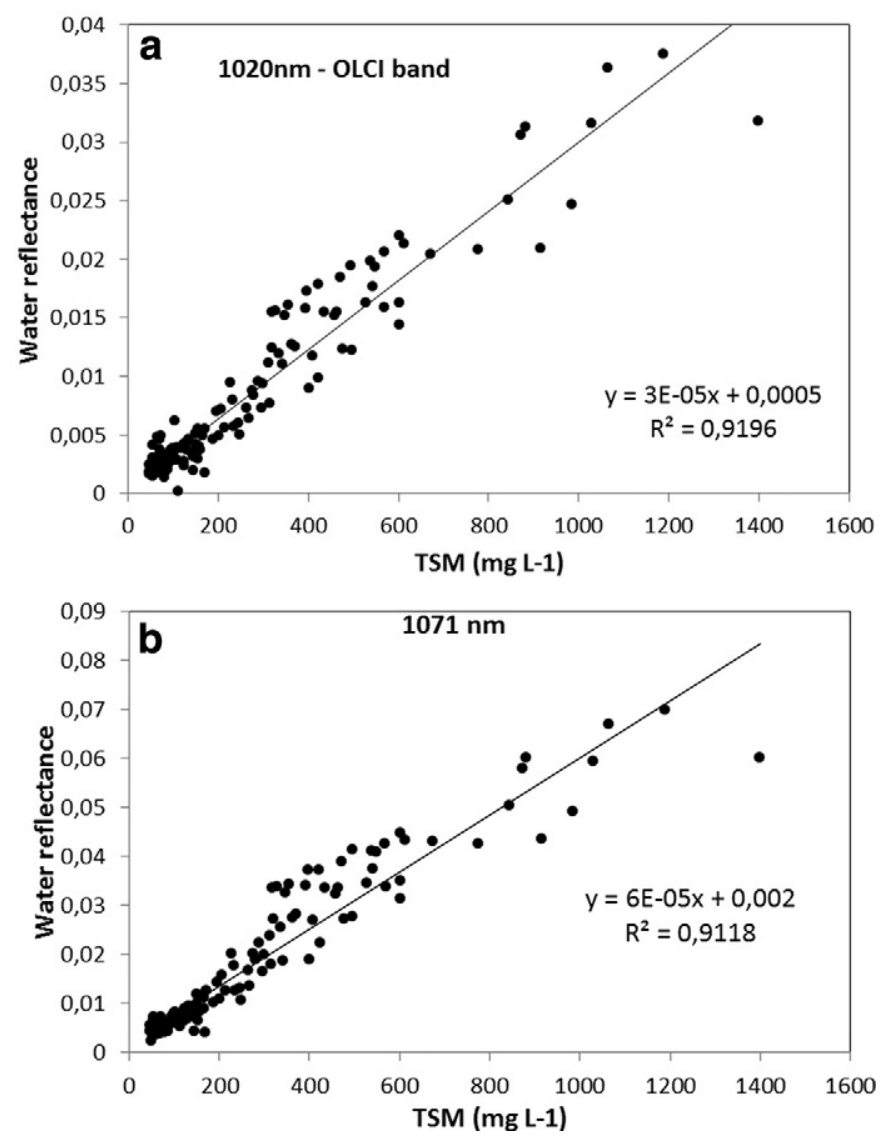

Fig. 5. Scatter pots of a) $R_{w 1020}$ and b) $R_{w 1071}$ versus the TSM concentration.

$12 \mathrm{~nm}$. The APEX radiometric, spectral, and geometric calibration is performed by means of calibration cubes generated from data measured and collected on the APEX Calibration Home Base (CHB) hosted at DLR Oberpfaffenhofen, Germany (Gege et al., 2009). The atmospheric correction and air-interface correction of the acquired APEX data is performed by the CDPC (Biesemans et al., 2007) with the MODTRAN4 radiative transfer code following the algorithms given in De Haan, Hovenier, Kokke, and Van Stokkom (1991) and De Haan and Kokke (1996).

Similar to the ASD processing, an extra white reflectance correction was performed for residual sky glint by subtracting the water reflectance at $1306 \mathrm{~nm}$ (i.e. wavelength closest to $1305 \mathrm{~nm}$ ). An additional visual check of the reflectance obtained at $1306 \mathrm{~nm}$ showed no

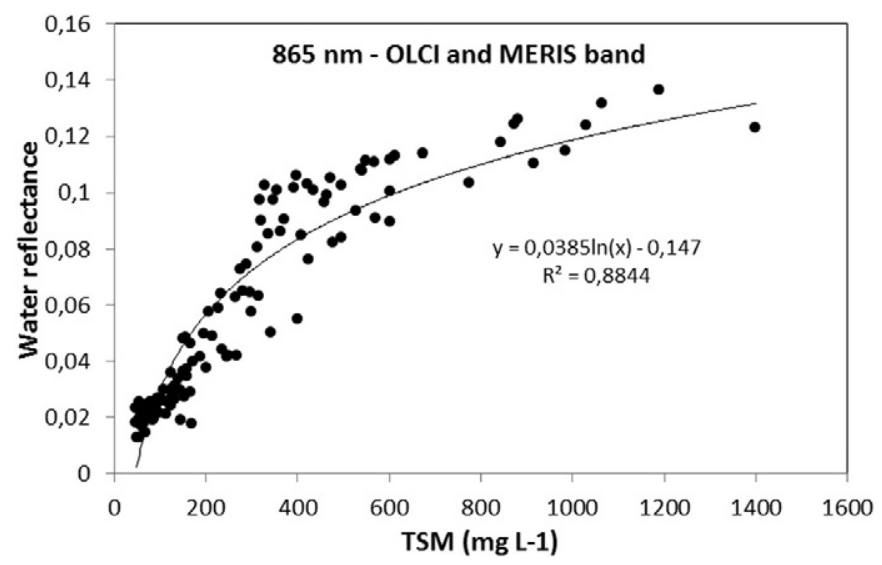

Fig. 6. Relationship between $\mathrm{R}_{\mathrm{w} 865}$ and TSM concentration. correlation between the reflectance at this wavelength and the turbidity of the water.

\subsection{Algorithm calibration}

Based on the in situ TSM concentration and ASD water reflectance measurements, a SWIR algorithm is developed empirically. To evaluate its performance the empirical SWIR algorithm is compared to a single band semi-analytical reflectance-based algorithm (Nechad et al., 2010) with its parameters extrapolated for the $1020 \mathrm{~nm}$ and $1071 \mathrm{~nm}$ SWIR wavelengths. The NIR based semi-analytical algorithm (Nechad et al., 2010) was originally developed based on a simplified reflectance model, based on a first order version of the model of Gordon et al. (1988) and calibrated using in situ data from the southern North Sea. The algorithm relates the reflectance in a single band to the TSM concentration according to:

$\mathrm{TSM}=\mathrm{A}^{\rho} \mathrm{R}_{\mathrm{W}}(\lambda) /\left(1-\mathrm{R}_{\mathrm{w}}(\lambda) / \mathrm{C}^{\rho}\right)$

with

Parameter $\mathrm{A}^{\rho}=\mathrm{A} / \gamma$

Asymptotic limit $C^{\rho}=\gamma C /(1+C)$

where

$$
\begin{aligned}
& \mathrm{A}=\mathrm{a}_{\mathrm{np}} / \mathrm{b}_{\mathrm{bp}}{ }^{*} \\
& \mathrm{C}=\mathrm{b}_{\mathrm{bp}}{ }^{*} / \mathrm{a}_{\mathrm{p}}{ }^{*} \\
& \text { and } \gamma=\pi \mathrm{R} \mathrm{f}^{\prime} / \mathrm{Q} .
\end{aligned}
$$

$\mathrm{f}^{\prime} / \mathrm{Q}$ is the bidirectionality factor, $\mathrm{b}_{\mathrm{bp}}{ }^{*}$ is the mass-specific particulate backscattering coefficient, $a_{p}{ }^{*}$ is the mass-specific particulate absorption coefficient and $\mathrm{a}_{\mathrm{np}}$ is the non-particulate absorption coefficient. Both parameters $\mathrm{A}^{\rho}$ and $\mathrm{C}^{\rho}$ have only been provided for wavelengths up to $885 \mathrm{~nm}$ (Nechad et al., 2010) and need to be recalibrated for the SWIR. For parameter $C^{\rho}, \gamma$ is first calculated by using $R=0.529$ from Morel and Gentilli (1996). For the bidirectionality factor $\mathrm{f}^{\prime} / \mathrm{Q}$ no parameterizations exist for these waters and these wavelengths. Therefore $\mathrm{f} / \mathrm{Q}$ is set to a constant value of 0.13 similar to Nechad et al. (2010) and derived by Loisel and Morel (2001) for sediment-dominated waters. This results in a $\gamma$ of 0.216 . Then $C$ is recalculated using the original datasets described in Nechad et al. (2010) and extrapolated to the SWIR. This gives a $C^{\rho}$ very close to $\gamma(0.2152$ for $1020 \mathrm{~nm}$ and 0.2156 for $1071 \mathrm{~nm}$ ). Finally $A^{\rho}$ is obtained by scaling of the pure water absorption coefficients ( $a_{w}$, see Fig. 1$)$ as in Dogliotti et al. (2011) following:

$A^{\rho}(\lambda)=A^{\rho}(865)\left(a_{w}(\lambda) / a_{w}(865)(\lambda / 865)^{n}\right.$

using $\mathrm{A}^{\rho}(865)=2971.93 \mathrm{mg} \mathrm{L}^{-1}$ from Nechad et al. (2010) and $\mathrm{n}=0.4$ as proposed by Dogliotti et al. (2011). Here $A^{\rho}$ is recalibrated for the SWIR at $1020 \mathrm{~nm}$ and $1071 \mathrm{~nm}$. The resulting algorithm is called hereafter the "SWIR based semi-analytical algorithm".

To evaluate the performance of the algorithms, the Mean Absolute Percentage Error (MAPE) is calculated as follows:

$\mathrm{MAPE}=100 \times \frac{1}{n} \sum_{i=1}^{n} \frac{\left[x_{i}-y_{i}\right]}{x_{i}}$

where $x_{i}$ is the field TSM concentration for sample $i$ and $y_{i}$ is the algorithm derived TSM concentration for sample i. 

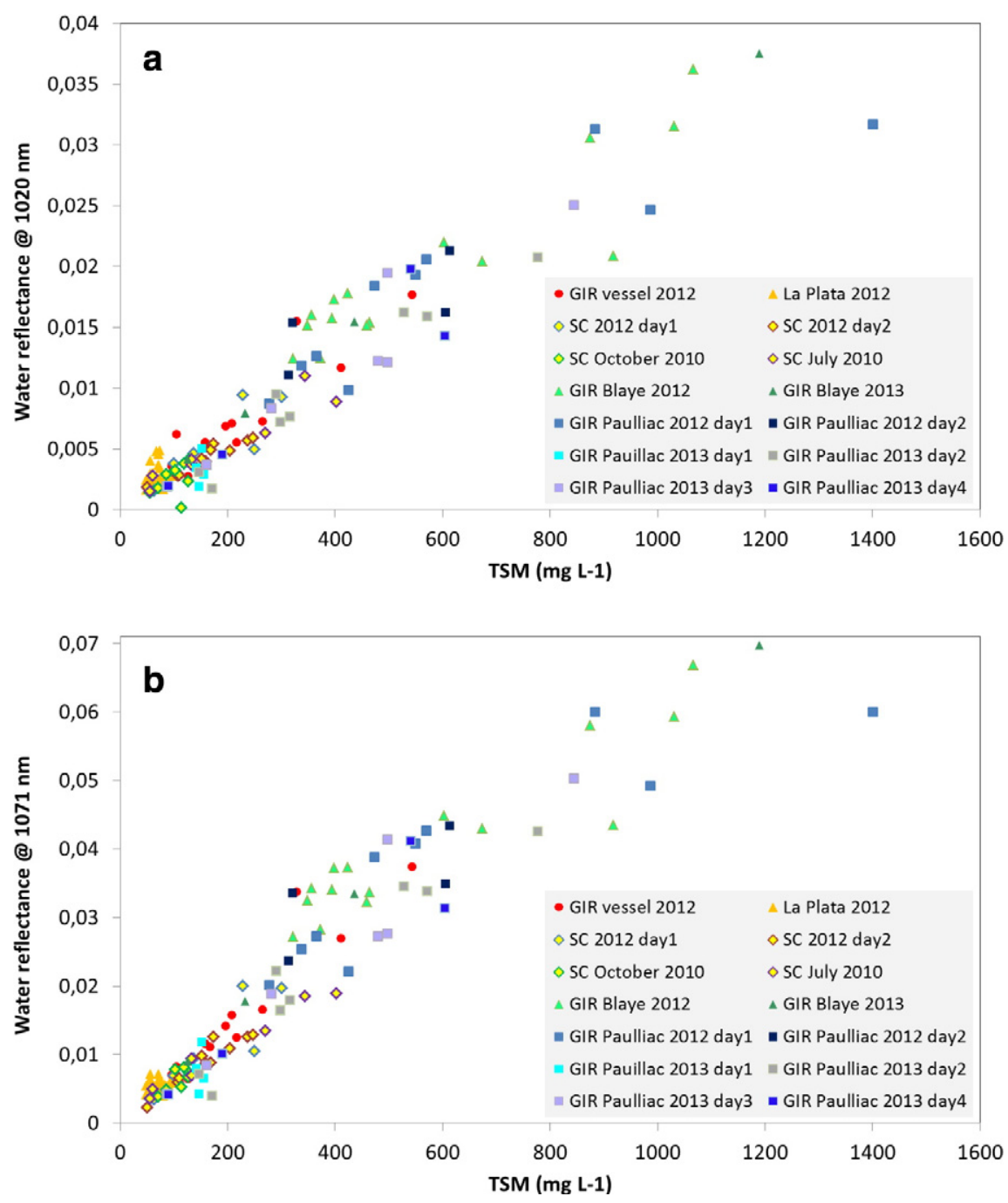

Fig. 7. Scatter plot of a) $\mathrm{R}_{\mathrm{w} 1020}$ and $\left.\mathrm{b}\right) \mathrm{R}_{\mathrm{w} 1071}$ versus $\mathrm{TSM}$ concentration for all individual datasets (GIR $=$ Gironde, $\left.S C=S c h e l d t\right)$.

\section{Results and discussion}

\subsection{Bio-optical properties of the estuarine waters}

The bio-optical properties of the three estuarine waters, including constituent concentrations, turbidity, salinity and temperature are shown in Table 5. Turbidity was not measured at all stations and does not cover the entire range of measurements. TSM concentrations

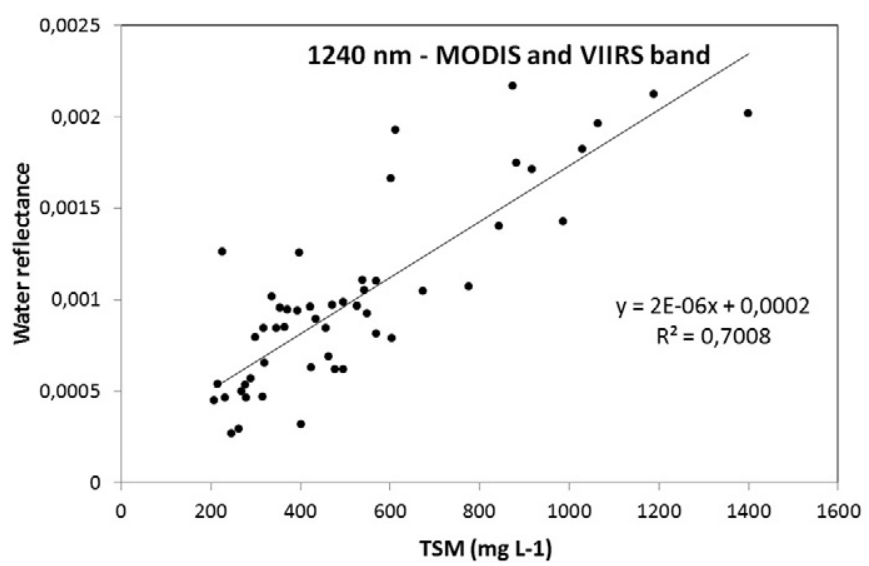

Fig. 8. Scatter plot of $\mathrm{Rw}_{1240}$ versus TSM concentration. measured over the three sites range from $30 \mathrm{mg} \mathrm{L}^{-1}$ up to extreme values of $1400 \mathrm{mg} \mathrm{L}^{-1}$. The highest concentrations were recorded at the Gironde when measuring on the pontoon of Paulliac, and the lowest at Río de la Plata. The TSM concentration generally followed the tidal cycle and could vary by one order of magnitude in a day. Based on the triplicates, the precision ( $\Delta \mathrm{t}=\mathrm{dTSM} / \mathrm{TSM}$ ) was excellent for the Scheldt and the Gironde ( $\Delta \mathrm{t}<5 \%$ on average) and for La Plata $(\Delta \mathrm{t} \sim 10 \%$ on average). Chla was analyzed for the Scheldt 2012 and Gironde 2012 campaigns showing a large difference between the two sites: high Chla content for the Scheldt ( $\max =71 \mu \mathrm{g} \mathrm{L}^{-1}$ ) and low for the Gironde $\left(\max =4.2 \mu \mathrm{g} \mathrm{L}^{-1}\right.$ ). Salinity ranged from 0.1 to $20.8 \mathrm{psu}$. The high salinity values were measured in the Gironde when sampling at the mouth of the estuary onboard the vessel. On the pontoons of the Scheldt and Gironde salinity followed the tidal cycle: salinity typically decreasing with freshwater supply during the ebb and increasing during flood. Continuous low salinity values were measured in La Plata. The water temperature ranged between $18.4{ }^{\circ} \mathrm{C}$ at the Gironde and $26.9{ }^{\circ} \mathrm{C}$ at $\mathrm{La}$ Plata.

\subsection{Analysis of the ASD water reflectance}

\subsubsection{ASD water reflectance quality control}

Fig. 3 shows the inter-comparison between $R_{w}$ from the ASD and $R_{w}$ from the Trios system at 6 different wavelengths. The data are highly correlated and close to the 1:1 line. Small deviations can be attributed partially to small scale local variability in water constituents between 

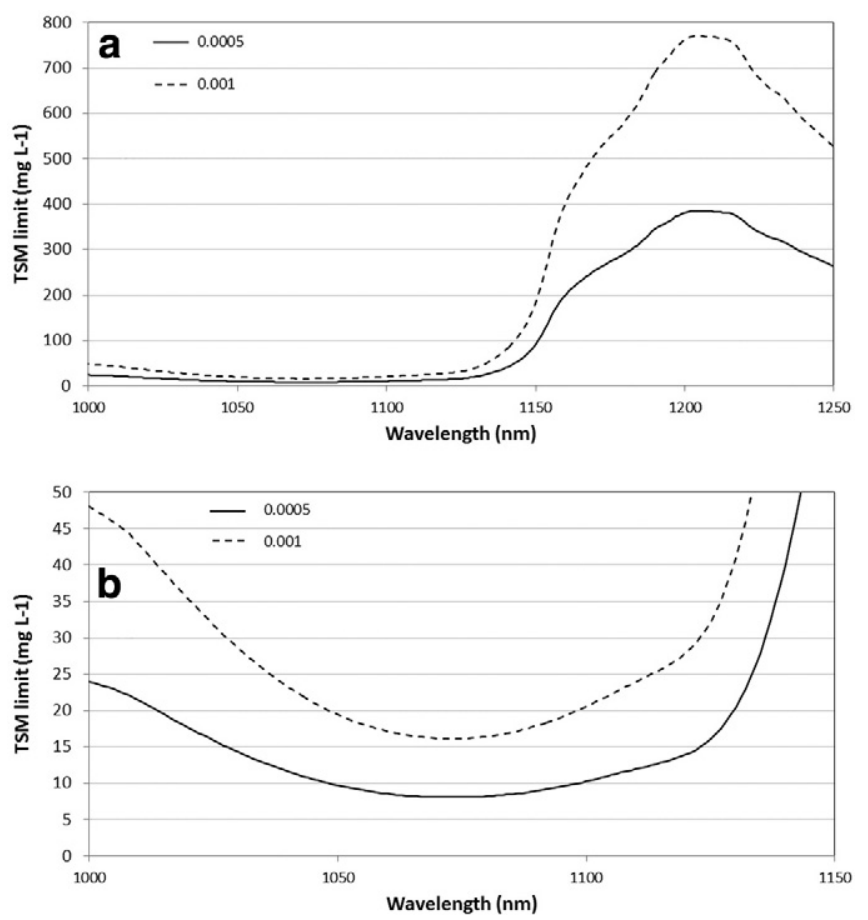

Fig. 9. TSM limits for SWIR-I and SWIR-II for two different levels of noise-equivalent reflectance. a) Shows the entire spectral region, b) zooms in on the TSM limits for SWIR-I.

the two measurement locations, a few metres apart, and/or between the two measurement times, typically synchronized to within five minutes. The shorter wavelengths (Fig. 3a) have a slightly better agreement than the longer wavelengths (Fig. $3 b)\left(R^{2}=0.97\right.$ versus $R^{2}=0.92$ ). From this we conclude that the measurements methodology and analysis of the ASD data is sound and can be used for further analysis.

\subsubsection{Typical water reflectance spectra}

Some typical water reflectance spectra, randomly chosen, with corresponding TSM concentration values for the sites are displayed in Fig. 4. Overall, these spectral signatures correspond very well to spectral signatures from extremely turbid waters reported in the literature (e.g. Doxaran, Cherukuru, \& Lavender, 2006; Doxaran et al., 2002 for the Gironde, Loire and Tamar estuaries; Islam et al., 2001 for the Ganges and Brahmaputra and Chen et al., 2014 for several inland and coastal waters in China).

The spectra for the Scheldt (Fig. 4a) have overall high reflectance values. Between 350 and $580 \mathrm{~nm}$ the reflectance is only weakly sensitive to variation in TSM. Between 580 and 720 nm maximum reflectance values are found up to 0.1 and the spectra reveal clear changes in shape and magnitude. In the NIR between 720 and $1000 \mathrm{~nm}$ there is more variability in the magnitude of the spectra and an increase in spectral reflectance can be observed with increasing TSM concentration. A significant signal can be observed in SWIR-I with maxima around 0.02 (at $1071 \mathrm{~nm}$ ) for TSM concentrations between 227 and $403 \mathrm{mg} \mathrm{L}^{-1}$. In SWIR-II the maximum reflectance is 0.001 at $1268 \mathrm{~nm}$. The shape of

Table 6

TSM concentration limits at $1020 \mathrm{~nm}$ and $1071 \mathrm{~nm}$.

\begin{tabular}{lcl}
\hline Wavelength & TSM limit $\left(\mathrm{mg} \mathrm{L}^{-1}\right)$ \\
\cline { 2 - 3 } & Noise equivalent reflectance & Noise equivalent reflectance \\
& 0.0005 & 0.001 \\
\hline $1020 \mathrm{~nm}$ & 16.4 & 32.7 \\
$1071 \mathrm{~nm}$ & 8.1 & 16.1 \\
$1240 \mathrm{~nm}$ & 282.6 & 565.2 \\
\hline
\end{tabular}

Table 7

$\mathrm{A}^{\rho}$ and $\mathrm{C}^{\rho}$ coefficients for the semi-analytical SWIR algorithm.

\begin{tabular}{lcl}
\hline SWIR wavelength & $\mathrm{A}^{\rho}(\mathrm{mg} \mathrm{L}-1)$ & $\mathrm{C}^{\rho}$ \\
\hline $1020 \mathrm{~nm}$ & $20,383.3$ & 0.2152 \\
$1071 \mathrm{~nm}$ & 9795.8 & 0.2156 \\
\hline
\end{tabular}

the water reflectance spectrum in the SWIR is clearly influenced by pure water absorption.

The spectra for La Plata are shown in Fig. 4b. All the spectra have a very similar shape and have only small differences in magnitude. They show a clear relationship with the TSM concentration beyond $580 \mathrm{~nm}$. Maximum reflectance values are found around $700 \mathrm{~nm}$ with values up to 0.1 . There is a very weak signal in SWIR-I (maximum 0.007 at $1071 \mathrm{~nm}$ for a TSM concentration of $74 \mathrm{mg} \mathrm{L}^{-1}$ ), while no significant signal in SWIR-II independently of the TSM concentration.

The Gironde spectra (Fig. 4c) have extremely high values, up to 0.2 around $700 \mathrm{~nm}$. A saturation effect is observed at the shorter wavelengths (between 350 and $580 \mathrm{~nm}$ ), followed by a spectral region with high reflectance (between 580 and $720 \mathrm{~nm}$ ), but no clear relationship with TSM is observed. In the NIR very large differences in reflectance values are observed which are clearly related to the TSM concentration. There is a high reflectance signal in SWIR-I (up to 0.07 ) and also a weak signal in SWIR-II. For SWIR-II, the highest reflectance signal measured is 0.0028 at $1276 \mathrm{~nm}$. At $1240 \mathrm{~nm}$ (MODIS and VIIRS band) a maximum reflectance of 0.0026 is measured. Two measurements have $\mathrm{R}_{\mathrm{w} 1240}$ above 0.002 and 6 measurements have $\mathrm{R}_{\mathrm{w} 1268}$ above 0.002 . These correspond to TSM concentrations between 874 and $1400 \mathrm{mg} \mathrm{L}^{-1}$. Also here, pure water absorption clearly influences the shape of the water reflectance spectrum in the SWIR.
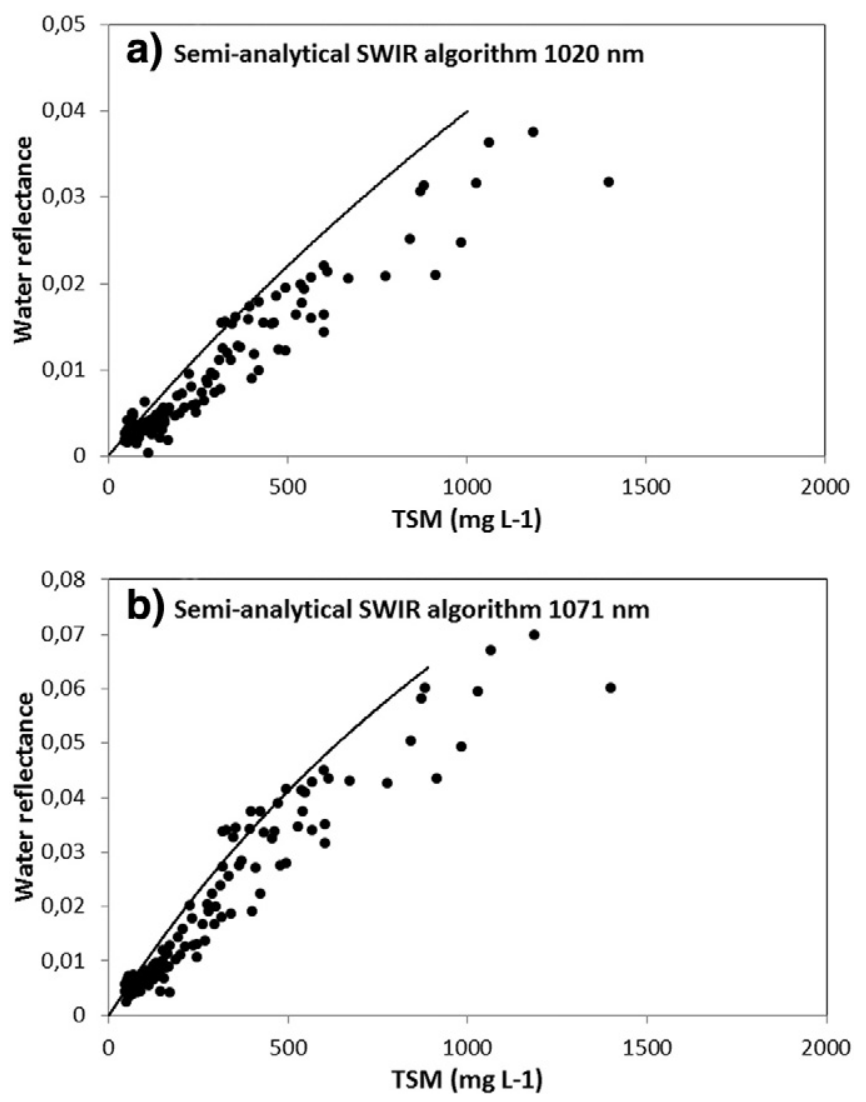

Fig. 10. Semi-analytical SWIR algorithm for a) $1020 \mathrm{~nm}$ and b) $1071 \mathrm{~nm}$. 
Table 8

Algorithm performance.

\begin{tabular}{|c|c|c|c|c|}
\hline Algorithm & Bands used & MAPE (\%) & $\begin{array}{l}\text { MAPE (\%) } \\
\text { (high TSM) }\end{array}$ & $\begin{array}{l}\text { MAPE (\%) } \\
\text { (low TSM) }\end{array}$ \\
\hline Single band empirical SWIR & 1020 & 25 & 21 & 27 \\
\hline Single band empirical SWIR & 1071 & 25 & 21 & 27 \\
\hline Single band semi-analytical SWIR & 1020 & 31 & 21 & 36 \\
\hline Single band semi-analytical SWIR & 1071 & 29 & 21 & 33 \\
\hline
\end{tabular}

\subsubsection{Relationship between $R_{w}$ and TSM concentration}

3.2.3.1. Scatterplots and SWIR TSM algorithm. Two wavelengths of prime interest are selected within the SWIR-I region and will be analyzed in detail in the scatter plots: $1020 \mathrm{~nm}$ (OLCI band) and $1071 \mathrm{~nm}$ (peak reflectance in SWIR-I). The scatter plots for the $1020 \mathrm{~nm}$ and $1071 \mathrm{~nm}$ band versus the TSM concentrations are shown in Fig. 5. Both datasets have a clear linear trend which explains $92 \%$ of the variation with only a small Y offset of $5.3910^{-4}$ and $1.9810^{-3}$ for the 1020 and $1071 \mathrm{~nm}$ bands, respectively. There is no sign of saturation (non-linearity) or decrease of sensitivity for the TSM concentrations measured in the study area (the maximum TSM concentration in the dataset is $1400 \mathrm{mg} \mathrm{L}^{-1}$ ). The relationships can be written as follows:

$\mathrm{TSM}=\mathrm{R}_{\mathrm{w} 1020} / 2.9410^{-5}-18.3$

$\mathrm{TSM}=\mathrm{R}_{\mathrm{w} 1071} / 5.8210^{-5}-34.0$.

With a MAPE of $26 \%$ for Eq. (5) and a MAPE of $25 \%$ for Eq. (6). The Y offset could be related to errors in the processing of the ASD data (e.g. errors in sky glint correction).

For comparison, a scatter plot of the reflectance at $865 \mathrm{~nm}$ (OLCI band 17, MERIS band 14) and the TSM concentration is shown in Fig. 6. Here, the trend in the data is approximately logarithmic with less sensitivity of the reflectance above a TSM concentration of $500 \mathrm{mg} \mathrm{L}^{-1}$ or a reflectance threshold of 0.09 . This is in agreement with Doxaran et al. (2002) where water reflectance at SPOT band XS3 (790-890 nm) from the Gironde is linearly proportional to TSM concentration up to $500 \mathrm{mg} \mathrm{L}^{-1}$ and then tends to saturate. Apart from this saturation effect, it is also observed that the performance of this single NIR band at $865 \mathrm{~nm}$ is lower $\left(\mathrm{r}^{2}=88 \%\right)$ than the performance from the SWIR bands $\left(r^{2}=92 \%\right)$.

3.2.3.2. Regionality of the algorithm. Fig. 7 shows again the 1020 and $1071 \mathrm{~nm}$ bands versus the TSM concentration. Here, all individual datasets are plotted in a different colour. Regardless of the differences in mineralogy and texture between the sites, the different sampling dates and sampling locations for each site, all datasets from the Scheldt and Gironde follow the general trend very well. The data from Río de la Plata on the other hand exhibit lower and narrower range of TSM concentrations showing no clear trend. The fact that a single relationship is observed for the different Gironde and Scheldt datasets means that one single algorithm is valid for both sites, for the different locations within the study sites, and the different dates of sampling.

3.2.3.3. SWIR-II analysis. The SWIR-II spectral region is further analyzed using the data points with TSM concentration above $200 \mathrm{mg} \mathrm{L}^{-1}$. Below this threshold the data are highly scattered because of the very low signal due to the high pure water absorption. For this reduced dataset $(\mathrm{n}=41)$ the correlation increases up to $70 \%$ at $1240 \mathrm{~nm}$ (MODIS, VIIRS bands) for a linear model. This band is available in MODIS and VIIRS and is used in the SWIR based atmospheric correction algorithm (Wang \& Shi, 2007). The scatter plot of the reflectance at this wavelength and the corresponding TSM concentrations are shown in Fig. 8. Although the scatter is larger than for SWIR-I, the linear trend is clearly visible with only a small $\mathrm{Y}$ offset. Although these results show a clear trend between the reflectance and TSM, the measured reflectance in the SWIR-II is very weak (most of the data points below reflectance threshold of 0.002 ).

3.2.3.4. TSM limits for the black pixel assumption. Based on the linear relationships of each spectral band in the SWIR and the corresponding TSM concentrations, limits for applying a black pixel assumption can be derived. Because the offsets observed for the linear relationships are attributed to errors in the measurements (due to e.g. incorrect sky glint correction), the trend line is forced through zero to calculate the TSM limits. These limits are shown in Fig. 9 for each wavelength within the SWIR-I and SWIR-II region and for a certain noise-equivalent water reflectance threshold. The TSM concentration limits have to be interpreted as a baseline below which we can safely apply a black pixel assumption. The TSM limits follows the shape of the pure water absorption with a minimum TSM limit around $1071 \mathrm{~nm}$. The exact TSM concentration limits for the two thresholds and spectral bands at 1020, 1071 and $1240 \mathrm{~nm}$ are provided in Table 6. Clearly, this TSM limit depends linearly on the reflectance threshold set. For a noiseequivalent reflectance threshold of 0.001 , the TSM limits are 16.4, 8.1 and $282.6 \mathrm{mg} \mathrm{L}^{-1}$ for the $1020 \mathrm{~nm}, 1071 \mathrm{~nm}$ and $1240 \mathrm{~nm}$ band respectively. Since these TSM limits are linearly related to the noise threshold, these values and Fig. 9 can be transposed to any other sensor noise level by simple linear scaling.

\subsubsection{TSM algorithm inter-comparison}

The performance of the empirical single band SWIR TSM algorithm (based on the $1020 \mathrm{~nm}$ and $1071 \mathrm{~nm}$ bands, Eqs. (5) and (6)) is compared to the performance of a single band semi-analytical algorithm (Nechad et al., 2010) recalibrated for the SWIR following:

$\mathrm{TSM}=\mathrm{A}^{\rho} \mathrm{R}_{\mathrm{w}}(\lambda) /\left(1-\mathrm{R}_{\mathrm{w}}(\lambda) / \mathrm{C}^{\rho}\right)$.

The calibration parameters $A^{\rho}$ and $C^{\rho}$ are presented in Table 7 for $1020 \mathrm{~nm}$ and $1071 \mathrm{~nm}$ and the relationships are shown in Fig. 10.

For each algorithm the MAPE is calculated for the entire dataset and separately for low (TSM $<300 \mathrm{mg} \mathrm{L}^{-1}$ ) and high (TSM $>300 \mathrm{mg} \mathrm{L}^{-1}$ ) concentrations. The statistics are presented in Table 8. Fig. 11 shows the scatter plots of the field TSM concentration versus the modelled TSM concentration for all algorithms. An extra scatter plot is shown zooming in on the low TSM concentrations (Fig. 11b, d, f and h).

Table 8 shows that the single band empirical SWIR TSM algorithms perform well for the entire dataset with a MAPE of 25\%. The semianalytical SWIR algorithms have a lower overall MAPE of 31 and 29\% for the 1020 and $1071 \mathrm{~nm}$ band respectively. Particularly at low TSM concentrations (TSM $<300 \mathrm{mg} \mathrm{L}^{-1}$ ) they perform worse (MAPE = $33-36 \%$ versus $\mathrm{MAPE}=27 \%$ for the empirical single band algorithms). The semi-analytical algorithms mostly underestimate the TSM concentration. A slightly different linear coefficient $\left(A^{\rho}\right.$, now based on scaling of aw) would be needed to better fit the dataset.

\subsubsection{Application of the SWIR algorithm to APEX images}

Fig. 12 shows some typical APEX water reflectance spectra from the mouth to more upstream regions of the Gironde estuary. The spectral region between 940 to $1020 \mathrm{~nm}$ should be treated with care due to artefacts near the strong water vapour bands, combined with some specific sensor related issues such as double peak spectral response curves for the last NIR bands, and a decrease of quantum efficiency at the end of 

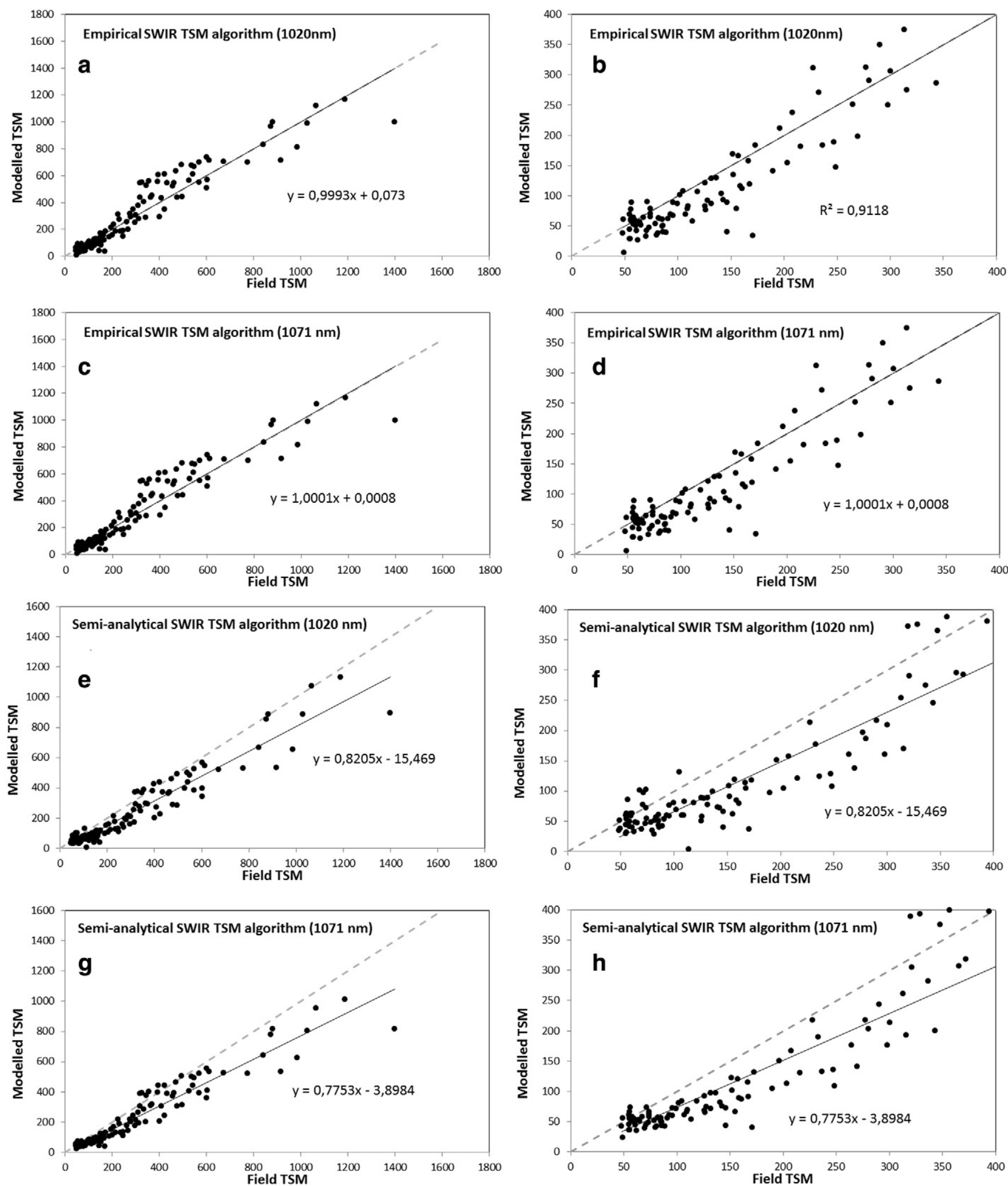

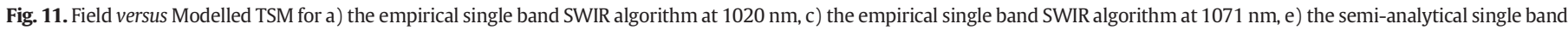

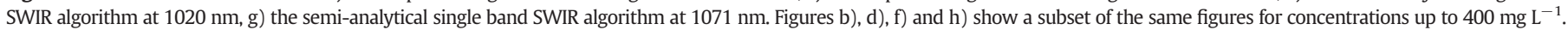

the detectors. Hence, these spectral bands were deleted in further analysis.

The overall shape and magnitude of the spectra are very similar to the ASD water reflectance spectra (Fig. 4c). Going more upstream, the reflectance increases and a high signal in SWIR-I can be observed. In SWIR-II the reflectance values are too noisy.

A TSM map was generated based on the SWIR TSM algorithm (for $1071 \mathrm{~nm}$ band, Eq. (5)) and is shown in Fig. 13. The flight line was 


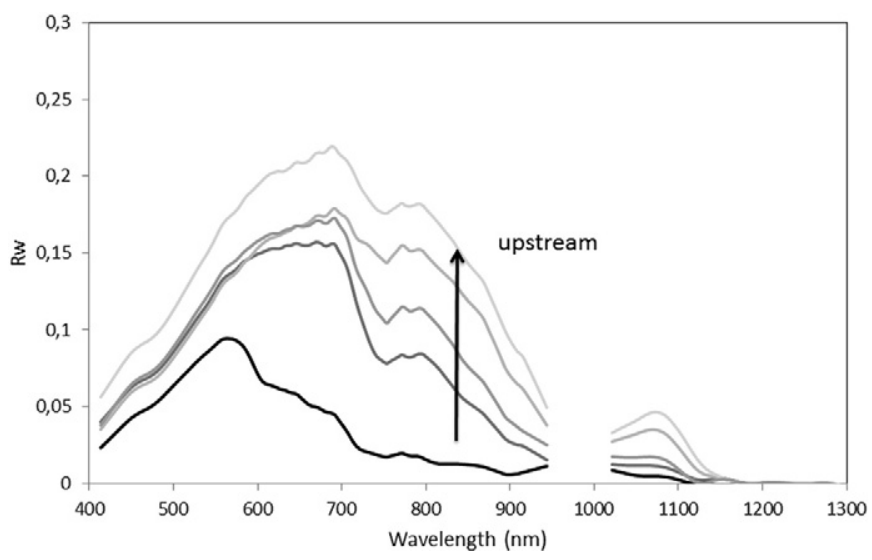

Fig. 12. APEX water reflectance from mouth to upstream.

acquired between 11:50 and 12:07 local time (UTC $+2 \mathrm{~h}$ ) on 14 June 2012.

In general TSM concentration increases from mouth to upstream and a turbidity maximum is observed around the islands in the southern part of the maps with TSM concentrations above $600 \mathrm{mg} \mathrm{L}^{-1}$. The TSM variations (and values) correspond to what was expected from the sampling conditions. A maximum turbidity zone (MTZ) is located in the middle estuary, in between the cities of Pauillac on the West shore and Blaye on the East shore, where several islands form an efficient trapping zone; it is known as a permanent MTZ only weakly influenced by the river discharge where TSM are trapped. From Doxaran et al. (2009) it is known that a second MTZ (as strongly influenced by the river freshwater discharge) is located upstream (not shown in Figure, not acquired by APEX) during the summer period.

Fig. 14 zooms in on the Blaye pontoon (in black) where the in situ data were collected on the day of the APEX acquisition. The water samples were collected at the most southern end of the pontoon. Only one sample (GIR38) was collected during the acquisition (start sampling time 11:58 local time) with a TSM concentration of $603 \mathrm{mg} \mathrm{L}^{-1}$. The concentrations derived from the APEX image and surrounding the pontoon range from 200 to $700 \mathrm{mg} \mathrm{L}^{-1}$. However in the most southern part of the pontoon we can observe a small plume with increased concentration around $600 \mathrm{mg} \mathrm{L}^{-1}$, corresponding to the field observations. In Fig. 14 (right) the TSM concentration of sample GIR38 is compared with the TSM concentrations from the samples before and after the image acquisition. It shows that in a time frame of only $2 \mathrm{~h}$ and 30 min the TSM concentration has tripled. Both these figures show the dynamic nature of the estuary in space and time and the difficulty to collect validation match-ups in these environments.

\section{Conclusion and recommendations}

In this study we provide an empirical single band SWIR TSM algorithm for the $1020 \mathrm{~nm}$ (OLCI band) and $1071 \mathrm{~nm}$ (maximum reflectance in the SWIR-I) bands. Such a SWIR based algorithm will be useful for extremely turbid waters where NIR bands saturate. It was shown that the relationship between the water reflectance at these SWIR bands and the TSM concentration is linear. No saturation or decrease of sensitivity was observed (for maximum concentration of $1400 \mathrm{mg} \mathrm{L}^{-1}$ ). In the NIR this saturation was clearly present as was shown for the $865 \mathrm{~nm}$ band (OLCI and MERIS band), starting at a reflectance threshold of 0.09. Above this threshold it is advised to switch to longer wavelengths to ensure good quality TSM estimates.

The relationship between water reflectance and TSM was used to provide TSM limits for application of a black pixel atmospheric correction algorithm in the SWIR-I and SWIR-II region, i.e. maximum TSM concentration below which the black pixel assumption can be safely applied. For a reflectance threshold of 0.001 , this TSM limit is $16.4 \mathrm{mg} \mathrm{L}^{-1}$ for a spectral band at $1020 \mathrm{~nm}$, the limit is $8.1 \mathrm{mg} \mathrm{L}^{-1}$ for a spectral band at $1071 \mathrm{~nm}$ and $282.6 \mathrm{mg} \mathrm{L}^{-1}$ for a spectral band at $1240 \mathrm{~nm}$. These values should be considered when applying an atmospheric correction which assumes a black pixel in these spectral bands. Exceedance of these limits may results in overestimation of the aerosol reflectance and may further lead to incorrect estimates of the coloured water constituents concentrations. Similar TSM limits may be set for other SWIR sensor noise levels by simple linear scaling of the values given at the reflectance thresholds in this paper.

The empirical SWIR algorithm was compared with an existing semianalytical algorithm (Nechad et al., 2010). The parameters of the semi-

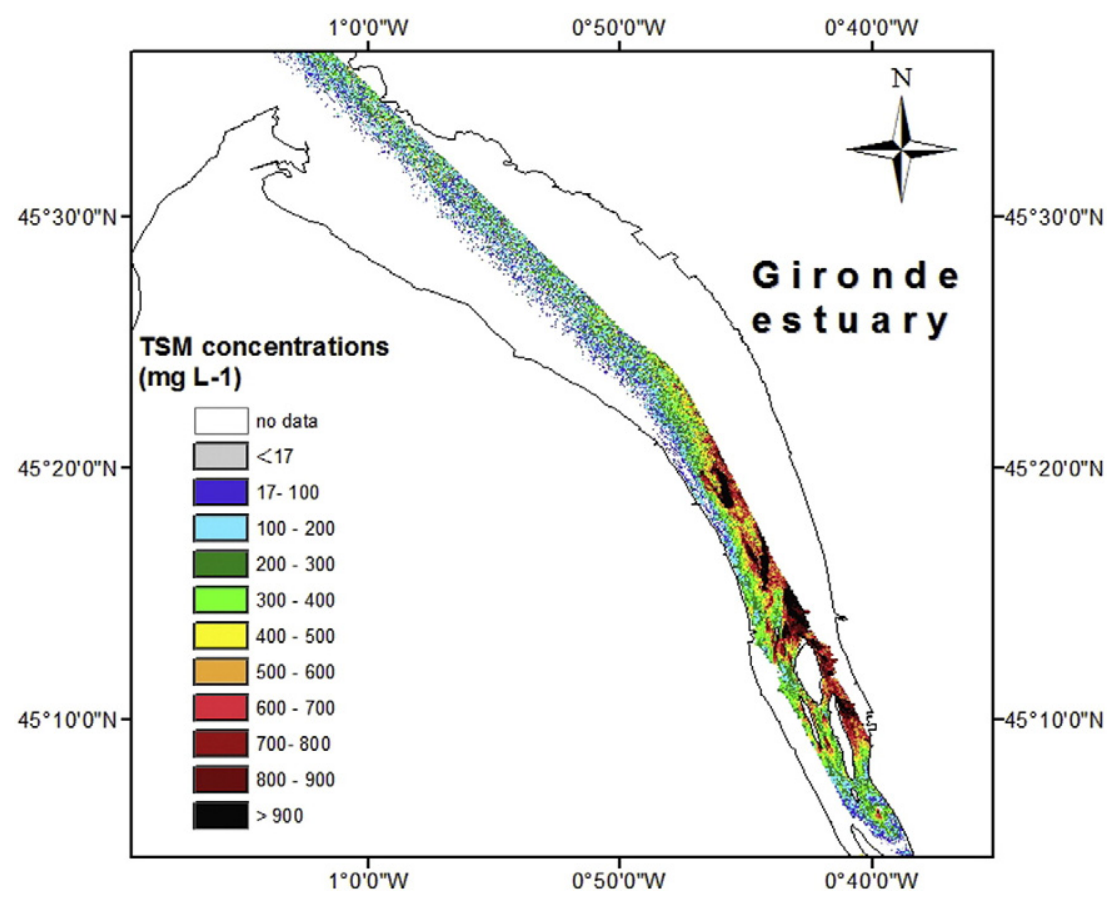

Fig. 13. TSM map from APEX from 14 June 2012, acquired between 09:50 and 10:07 UTC. 

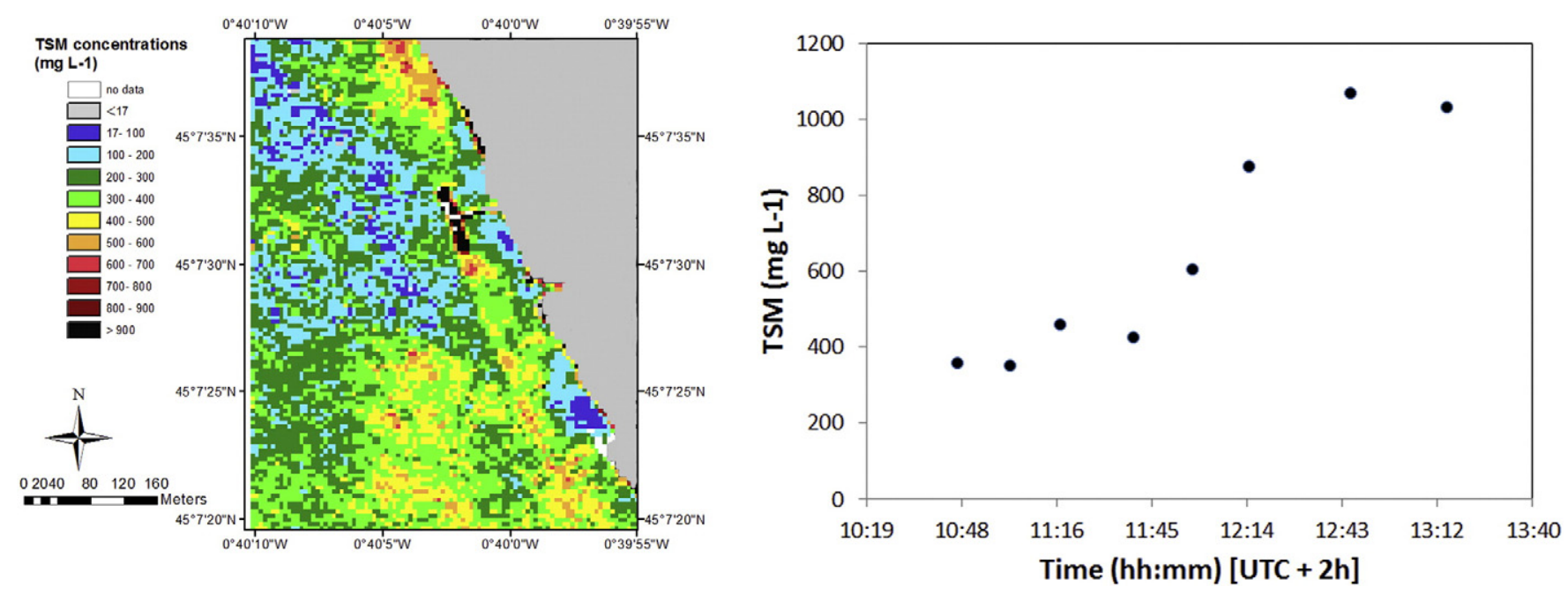

Fig. 14. Left: TSM map from APEX zooming in on the Blaye pontoon. Right: in situ TSM concentrations around the time of image acquisition.

analytical algorithm were extrapolated to the SWIR but were not recalibrated for the present dataset. The empirical single band algorithm calibrated for the site of interest outperformed the semi-analytical algorithm. This also shows that the semi-analytical algorithm might need recalibration of the $A^{\rho}$ parameter to better fit the dataset.

These results have shown a considerable added value of having SWIR bands on future ocean colour sensors to enhance performance for extremely turbid waters such as the world's major river plumes (Yangtze, Amazon, MacKenzie, etc.) and the many extremely turbid estuaries and inland waters. If cost precludes inclusion of a full SWIR range detector $(1-3 \mu \mathrm{m})$ on future sensors, the inclusion of at least a single SWIR band, e.g. $1020 \mathrm{~nm}$ as on OLCI, already gives significant extra information compared to the VIS/NIR bands. Further research should focus on performance assessment of SWIR-I bands on existing/planned sensors, in particular clarification of the necessary SNR requirements for exploitation of silicon-based detectors with a single SWIR-I band, e.g. the OLCI $1020 \mathrm{~nm}$ band.

Finally, to fully exploit the $1020 \mathrm{~nm}$ band of the OLCI sensor for TSM retrieval in these extremely turbid waters, we should be able to provide an operational atmospheric correction to routinely retrieve from satellite data the water reflectance at $1020 \mathrm{~nm}$.

\section{Acknowledgement}

The research leading to these results has received funding from the Belgian Science Policy Office through the STEREO programme (SeaSWIR project) and the European Community's Seventh Framework Programme (FP7/2007-2013) under grant agreement nº 606865 (INFORM project).

\section{References}

Aurin, D. A., \& Dierssen, H. M. (2012). Advantages and limitations of ocean color remote sensing in CDOM-dominated, mineral-rich coastal and estuarine waters. Remote Sensing of Environment, 125, 181-197.

Aurin, D. A., Dierssen, H. M., Twardowski, M., \& Roesler, C. (2010). Optical complexity in Long Island Sound and implications for coastal ocean color remote sensing. Journal of Geophysical Research, 115

Biesemans, J., Sterckx, S., Knaeps, E., Vreys, K., Adriaensen, S., Hooyberghs, J., et al. (2007). Image processing workflows for airborne remote sensing. Proceedings 5th EARSeL Workshop on Imaging Spectroscopy, Bruges, Belgium, April 23-25 2007.

Blondeau-Patissier, D., Brando, V. E., Oubelkheir, K., Dekker, A. G., Clementson, L. A., \& Daniel, P. (2009). Bio-optical variability of the absorption and scattering properties of the Queensland inshore and reef waters, Australia. Journal of Geophysical Research, 114, 1-24.

Bowers, D. G., Boudjelas, S., \& Harker, G. E. L. (1998). The distribution of fine suspended sediments in the surface waters of the Irish Sea and its relation to tidal stirring. International Journal of Remote Sensing, 19(14), 2789-2805.
C.A.R.P. (1989). Estudio para la evaluación de la contaminación en el Río de la Plata. Capítulo I. Aspectos Geológicos. Buenos Aires: Comisión Administradora del Río de la Plata, 1-72.

Castaing, P. (1981). Le transfert à l'océan des suspensions estuariennes. Cas de la Gironde. (State PhD Thesis) University Bordeaux 1 ( $\mathrm{n}^{\circ} 701,530$ pp.).

Chen, M. S., Wartel, S., Van Eck, B., \& Van Maldegem, D. (2005). Suspended matter in the Scheldt estuary. Hydrobiologia, 540, 79-104.

Chen, J., Yin, S., Xiao, R., Xu, Q., \& Lin, C. (2014). Deriving remote sensing reflectance from turbid case II waters using green-shortwave infrared bands based model. Advances in Space Research, 53(8), 1229-1238.

De Haan, J. F., Hovenier, J. W., Kokke, J. M. M., \& Van Stokkom, H. T. C. (1991). Removal of atmospheric influences on satellite-borne imagery: a radiative transfer approach. Remote Sensing of Environment, 37, 1-21.

De Haan, J. F., \& Kokke, J. M. M. (1996). Remote sensing algorithm development toolkit Operationalization of atmospheric correction methods for tidal and inland waters. (Netherlands Remote Sensing Board (BCRS) publication (pp. 91). Rijkswaterstaat Survey Dept. Technical Report.

Depetris, P. J., \& Griffin, J. J. (1968). Suspended load in the Rio de la Plata drainage basin. Sedimentology, 11, 53-60.

Doerffer, R. (2006). MERIS case 1 validation: Performance of the NN case 2 water algorithm for case 1 water. MERIS Validation Team Meeting, ESA ESRIN, Frascati, 20-24 March, 2006.

Dogliotti, A. I., Ruddick, K. G., Nechad, B., Doxaran, D., \& Knaeps, E. (2015). A single algorithm to retrieve turbidity from remotely-sensed data in all coastal and estuarine waters. Remote Sensing of Environment, 156, 157-168.

Dogliotti, A. I., Ruddick, K., Nechad, B., \& Lasta, C. (2011). Improving water reflectance retrieval from MODIS imagery in the highly turbid waters of La Plata River Proceedings of VI International Conference "Current Problems in Optics of Natural Waters". St. Petersburg, Russia: Publishing House "Nauka" of RAS.

Doron, M., Bélanger, S., Doxaran, D., \& Babin, M. (2011). Spectral variations in the nearinfrared ocean reflectance. Remote Sensing of Environment, 115(7), 1617-1631.

Doxaran, D., Cherukuru, R. C. N., \& Lavender, S. J. (2006). Inherent and apparent optical properties of turbid estuarine waters: measurements, modelling and application to remote sensing. Applied Optics, 45, 2310-2324.

Doxaran, D., Froidefond, J. M., Castaing, P., \& Babin, M. (2009). Dynamics of the turbidity maximum zone in a macrotidal estuary (the Gironde, France): Observations from field and MODIS satellite data. Estuarine, Coastal and Shelf Science, 81, 321-332.

Doxaran, D., Froidefond, J. M., Lavender, S., \& Castaing, P. (2002). Spectral signature of highly turbid waters application with SPOT data to quantify suspend particulate matter concentrations. Remote Sensing of Environment, 81, 149-161.

Etcheber, H. (1978). Etude de la repartition et du comportement de quelques oligo-éléments métalliques ( $\mathrm{Zn}, \mathrm{Pb}, \mathrm{Cu}$ et $\mathrm{Ni}$ ) dans le complexe fluvio-estuarien de la Gironde. (State PhD Thesis) France: University Bordeaux 1 (209 pp.).

Gege, P., Fries, J., Haschberger, P., Schötz, P., Schwarzer, H., Strobl, P., et al. (2009). Calibration facility for airborne imaging spectrometers. ISPRS Journal of Photogrammetry E' Remote Sensing, 64, 387-397.

Gordon, H. R., Brown, O. B., Evans, R. H., Brown, J. W., Smith, R. C., Baker, K. S., et al. (1988). A semianalytical radiance model of ocean color. Journal of Geophysical Research 93(D9), 10909-10924.

Islam, M. R., Begun, S. F., Yamaguchi, Y., \& Ogawa, K. (2001). Suspend sediments in the Ganges and Brahmaputra Rivers in Bangladesh: Observation from TM and AVHRR data. Hydrological Processes, 15, 493-509.

Knaeps, E., Raymaekers, D., Sterckx, S., Ruddick, K., \& Dogliotti, A. I. (2012). In-situ evidence of non-zero reflectance in the OLCI $1020 \mathrm{~nm}$ band for a turbid estuary. Remote Sensing of Environment, 120, 133-144 (Sentinel Special issue).

Kou, L., Labrie, D., \& Chylek, P. (1993). Refractive índices of water and ice in the 0.65-2. $5 \mathrm{~m}$ spectral range. Applied Optics, 32, 3531-3540.

Latouche, C. (1971). Etude des minéreaux argileux des formations graveleuse PlioQuaternaires des feuilles géologiques au 1/80000 de Bordeaux et de Lesparre. Bulletin du Bureau de Recherches Géologique et Minières, Section 1(1), 25-34. 
Loisel, H., \& Morel, A. (2001). Non-isotropy of the upward radiance field in typical coastal (Case 2) waters. International Journal of Remote Sensing, 22(2 \& 3), 275-295.

López Laborde, J., \& Nagy, G. J. (1999). Hydrography and sediment transport. In G. M. Perillo, E. M. Pino, \& M. C. Piccolo (Eds.), Characteristics of the Rio de la Plata. Estuaries of South America: Their geomorphology and dynamics (pp. 137-159). Berlin: SpringerVerlag (Chap. 7).

Mobley, C. D. (1999). Estimation of the remote-sensing reflectance from above-surface measurements. Applied Optics, 38, 7442-7455.

Moore, G., Lavender, S., Kratzer, S., Icely, J., \& Huot, J. -P. (2010). The MERIS bright pixe atmospheric correction: evolution, performance assessment and validation for the MERIS 3rd reprocessing. Proceedings of the Ocean Optics XX conference held in Anchorage, USA, 27th September-1st October 2010.

Morel, A., \& Gentilli, B. (1996). Diffuse reflectance of oceanic waters. III. Implication of bidirectionality for the remote-sensing problem. Applied Optics, 30(30), 4427-4438.

Nechad, B., Ruddick, K. G., \& Park, Y. (2010). Calibration and validation of a generic multisensor algorithm for mapping of Total Suspended Matter in turbid waters. Remote Sensing of Environment, 114(4), 854-866.

Pope, R. M., \& Fry, E. S. (1997). Absorption spectrum (380-700 nm) of pure water. II. Integrating cavity measurements. Applied Optics, 36, 8710-8723.

Röttgers, R., Brockmann, C., Doerffer, R., Fischer, J., Hollstein, A., Lavender, S., et al. (2012). STSE-WaterRadiance, final report.
Ruddick, K. G., Cauwer, V. D., Park, Y. J., \& Moore, G. (2006). Seaborne measurements of near infrared water-leaving reflectance: The similarity spectrum for turbid waters. Limnology and Oceanography, 51, 1167-1179.

Shen, F., Salama, S., Zhou, Y., Li, J., Su, Z., \& Kuang, D. (2010). Remote-sensing reflectance characteristics of highly turbid estuarine waters - A comparative experiment of the Yangtze River and the Yellow River. International Journal of Remote Sensing, 31(10), 2639-2654.

Shi, W., \& Wang, M. (2009). An assessment of the black ocean pixel assumption for MODIS SWIR bands. Remote Sensing of Environment, 113, 1587-1597.

Shi, W., \& Wang, M. (2014). Ocean reflectance spectra at the red, near-infrared, and shortwave infrared from highly turbid waters: A study in the Bohai Sea, Yellow Sea, and East China Sea. Limnology and Oceanography, 59(2), 427-444.

Wang, M., \& Shi, W. (2007). The NIR-SWIR combined atmospheric correction approach for MODIS ocean color data processing. Optics Express, 15, 15722-15733.

Zibordi, G., Mélin, F., Berthon, J. -F., Holben, B., Slutsker, I., Giles, D., et al. (2009). AERONET-OC: A network for the validation of ocean color primary products. Journal of Atmospheric and Oceanic Technology, 26, 1634-1651. 